\title{
Characterization of the LOV1-Mediated, Victorin-Induced, Cell-Death Response with Virus-Induced Gene Silencing
}

\author{
Brian M. Gilbert and Thomas J. Wolpert \\ Department of Botany and Plant Pathology, Oregon State University, Corvallis 97331, U.S.A.
}

Submitted 14 January 2013. Accepted 11 April 2013.

\begin{abstract}
Victoria blight, caused by Cochliobolus victoriae, is a disease originally described on oat and recapitulated on Arabidopsis. $C$. victoriae pathogenesis depends upon production of the toxin victorin. In oat, victorin sensitivity is conferred by the $\mathrm{Vb}$ gene, which is genetically inseparable from the $P c 2$ resistance gene. Concurrently, in Arabidopsis, sensitivity is conferred by the LOCUS ORCHESTRATING VICTORIN EFFECTS1 (LOV1) gene. LOV1 encodes a nucleotide-binding site leucine-rich repeat protein, a type of protein commonly associated with disease resistance, and LOV1 "guards" the defense thioredoxin, TRX-h5. Expression of LOVI and TRX-h5 in Nicotiana benthamiana is sufficient to confer victorin sensitivity. Virus-induced gene silencing was used to characterize victorin-induced cell death in $N$. benthamiana. We determined that SGT1 is required for sensitivity and involved in LOV1 protein accumulation. We screened a normalized cDNA library and identified six genes that, when silenced, suppressed LOV1-mediated, victorininduced cell death and cell death induced by expression of the closely related $R P P 8$ resistance gene: a mitochondrial phosphate transporter, glycolate oxidase, glutamine synthetase, glyceraldehyde 3-phosphate dehydrogenase, and the Pand T-protein of the glycine decarboxylase complex. Silencing the latter four also inhibited cell death and disease resistance mediated by the $P T O$ resistance gene. Together, these results provide evidence that the victorin response mediated by $L O V 1$ is a defense response.
\end{abstract}

Victoria blight, a disease originally described on oat (Avena sativa), is caused by the necrotrophic fungus Cochliobolus victoriae (Meehan and Murphy 1946). Victoria blight exclusively appeared on oat plants carrying the crown rust resistance $(R)$ gene $P c 2$, which confers resistance to the biotrophic fungus Puccinia coronata (Litzenberger 1949). C. victoriae pathogenesis is dependent on production of victorin, a peptide, hostselective toxin (Macko et al. 1985; Meehan and Murphy 1947; Wolpert et al. 1985). Sensitivity to victorin is conferred by the dominant $V b$ gene in oat. Only oat plants sensitive to victorin are susceptible to $C$. victoriae, and oat plants treated with victorin alone display symptoms of Victoria blight (Meehan and Murphy 1947). Various genetic and mutagenic efforts to separate Victoria blight susceptibility from crown rust resistance

Corresponding author: T. Wolpert;

E-mail: wolpertt@science.oregonstate.edu

* The $e$-Xtra logo stands for "electronic extra" and indicates that two supplementary figures and one supplementary table are published online.

(C) 2013 The American Phytopathological Society have failed, suggesting that $P c 2$ and $V b$ are the same gene (Luke et al. 1966; Mayama et al. 1995; Rines and Luke 1985; Welsh et al. 1954). Thus, genetic evaluations indicate that Victoria blight susceptibility in oat is associated with an $R$ gene. Consistent with the genetic data, victorin elicits a response in sensitive oat plants (i.e., those containing $V b$ ) that resembles a defense response. This response includes callose deposition, a respiratory burst, lipid peroxidation, ethylene evolution, extracellular alkalization, phytoalexin synthesis, and $\mathrm{K}+$ efflux (Mayama et al. 1986; Navarre and Wolpert 1999a; Romanko 1959; Shain and Wheeler 1975; Ullrich and Novacky 1991; Walton and Earle 1985; Wheeler and Black 1963). Notably, victorin also induces a programmed cell death (PCD) response, which involves a mitochondrial permeability transition (MPT) (Coffeen and Wolpert 2004; Curtis and Wolpert 2002, 2004; Navarre and Wolpert 1999a; Tada et al. 2001; Yao et al. 2001, 2002). This PCD response shares characteristics with the hypersensitive response (HR), a form of PCD associated with disease resistance (Mur et al. 2008).

Victorin sensitivity and susceptibility to $C$. victoriae was identified in Arabidopsis (Lorang et al. 2004), and victorin-induced cell death in Arabidopsis was shown to share characteristics of PCD in oat (Wolpert et al. 2011) and the HR (Lorang et al. 2007). Victorin sensitivity and disease susceptibility in Arabidopsis is conferred by a single dominant gene designated LOCUS ORCHESTRATING VICTORIN EFFECTS1 (LOV1) (Lorang et al. 2007). LOV1 encodes a nucleotide-binding site leucine-rich repeat (NB-LRR) protein which is a class of proteins typically associated with disease resistance (Nimchuk et al. 2003). LOV1 is a member of the RPP8 family of proteins, of which all other members with known functions are involved in disease resistance (Cooley et al. 2000; Lorang et al. 2007; McDowell et al. 1998; Takahashi et al. 2002). NB-LRR proteins act as immune receptors, directly or indirectly recognizing pathogen effectors (Dangl and Jones 2001). Pathogens produce effectors to promote virulence (Dangl and McDowell 2006). Recognition of pathogen effectors results in effector-triggered immunity (ETI) (Jones and Dangl 2006). Effective ETI leads to a decrease in pathogen growth and typically includes the HR (Greenberg and Yao 2004).

The HR is thought to be an effective defense against biotrophic pathogens, which derive nutrients from living host tissue (Glazebrook 2005). PCD associated with the HR surrounding the infection site halts the spread of infection by limiting access to nutrients and water (Glazebrook 2005; Heath 2000). C. victoriae is characterized as a necrotrophic pathogen, which actively kills host tissue and extracts nutrients from dead cells. For necrotrophic pathogens, the HR may actually be beneficial and could promote susceptibility (Govrin and Levine 2000, Wolpert et al. 2002). For the necrotroph Botrytis cinerea, the HR has been shown to aid in pathogenicity by providing a 
growth substrate (Govrin and Levine 2000). Induction of the HR by the hemibiotrophic fungus Mycosphaerella graminicola is hypothesized to play an important role in its pathogenicity on wheat (Keon et al. 2007; Rudd et al. 2008). The similarities of victorin-induced cell death with the HR, the association of $V b$ with the $P c 2$ rust $R$ gene, and the finding that LOVI belongs to a family of disease $R$ genes all suggest that $C$. victoriae coopts the defensive HR to derive nutrients from the host.

A screen for ethylmethane sulphonate (EMS)-induced loss of sensitivity in Arabidopsis identified TRX-h5 as a protein required for LOV1 function (Sweat and Wolpert 2007). LOV1 is activated (induces cell death) when TRX-h5 binds victorin (Lorang et al. 2012). TRX-h5 is also required for the redoxmediated control of NPR1 (nonexpresser of pathogenesisrelated $[\mathrm{PR}]$ protein 1), a transcriptional co-regulator (Tada et al. 2008). NPR1 regulates changes in defense gene expression in response to pathogens (Kinkema et al. 2000). Due to its role in defense, TRX-h5 is a likely target for pathogen effectors. In the absence of LOV1, victorin displays properties of a "typical" virulence effector by inhibiting TRX-h5 catalytic function and, thereby, interfering with defense mediated by NPR1 (Lorang et al. 2012). This property of victorin increases the virulence of Pseudomonas syringae pv. maculicola but appears to provide no advantage to $C$. victoriae (Lorang et al. 2012). Conversely, in the presence of LOV1, victorin binding to TRX-h5 leads to LOV1 activation and cell death and pathogenesis by $C$. victoriae (Lorang et al. 2012). These findings support the interpretation that LOV1 functions in ETI as an R protein guarding TRX-h5 from effectors that targets thioredoxins. Thus, mechanistic studies also support the contention that C. victoriae is co-opting the HR.

The purpose of this work was to find genes other than LOVI and $T R X-h 5$ required for the victorin response to further characterize the nature of victorin-mediated cell death and clarify its relationship with ETI. Here, we exploit the finding that coexpression of Arabidopsis LOVI and TRX-h5 in Nicotiana benthamiana confers victorin sensitivity (Lorang et al. 2012). We used the Tobacco rattle virus (TRV)-based virus-induced gene silencing (VIGS) system to screen for additional genes involved in victorin-mediated cell death in $N$. benthamiana. VIGS employs RNA interference as a tool for reverse genetics to analyze gene function (Baulcombe 1999, Lu et al. 2003). A gene of interest is inserted into the viral vector and, upon infection, double-stranded RNA of the inserted gene is produced, leading to silencing of host mRNAs that contain sequence homology. This approach offered several advantages over the previous EMS mutagenesis screen that identified TRX-h5 (Sweat and Wolpert 2007). Unlike EMS mutagenesis, VIGS can silence multiple members of a gene family if the insert contains sequences conserved across all family members, and VIGS can be used to study genes with roles in both cell death and development while avoiding embryonic lethality (Lu et al. 2003). Therefore, the use of VIGS had the potential to identify additional components required for victorin-mediated cell death.

We show that genes involved in metabolic activity, a mitochondrial phosphate transporter (PHT), and the SUPPRESSOR OF G2 ALLELE OF SKP1 (SGT1) are required for victorin sensitivity. The metabolic enzymes found to be important were glyceraldehyde 3-phosphate dehydrogenase (GAPB) and four photorespiratory enzymes: glycolate oxidase (GOX), glutamine synthetase (GLU), the P protein of the glycine decarboxylase complex (GDC-P), and the T protein of the GDC (GDC-T). These metabolic enzymes were also required for cell death induced by transient expression of the $R P P 8 R$ gene and an autoactive form of PTO (PTOY207D). Silencing of these metabolic genes also reduced PTO-mediated resistance to $P$. syringae pv. tabaci in $N$. benthamiana, demonstrating a role for these genes in resistance conferred by ETI. Together, these results provide evidence that the victorin-mediated response is functionally equivalent to a resistance response.

\section{RESULTS}

\section{VIGS establishes that SGT1 is required for victorin-mediated cell death.}

Victorin sensitivity in $N$. benthamiana, conferred by transient co-expression of LOV1 and TRX-h5 (Lorang et al. 2012), demonstrates that any additional genes necessary for victorinmediated cell death are present in $N$. benthamiana. Victorin sensitivity in $N$. benthamiana was utilized to identify other genes required for victorin-mediated cell death. $N$. benthamiana plants were infected with a TRV vector (Liu et al. 2002) containing a fragment of a host gene to be silenced by VIGS. After gene silencing, LOVI and $T R X-h 5$ were transiently overexpressed in the leaves and the extent of the cell death following victorin treatment was visually assessed. Additionally, an electrolyte leakage assay was developed to quantify victorinmediated cell death in $N$. benthamiana. Leaf disks were excised from silenced plants expressing LOV1/TRX-h5. Negative controls employed plants infected with a construct to silence expression of GREEN FLUORESCENT PROTEIN (TRV:GFP) to control for viral effects in VIGS experiments. Conductance was measured to quantify electrolyte leakage, an indicator of cell death, over the course of $12 \mathrm{~h}$ after exposing the leaf disks to victorin (Fig. 1). Electrolyte leakage increased over time, fitting a typical sigmoidal curve, and approached saturation 12 $\mathrm{h}$ after exposure to victorin (Fig. 1A). Electrolyte leakage increased appreciably as victorin concentration was increased in half-log increments from 10 to $1,000 \mathrm{ng} / \mathrm{ml}$ (Fig. 1A). As victorin concentration was increased logarithmically, leakage increased linearly at all times tested, including 2, 4, 6, 8, and $12 \mathrm{~h}\left(R^{2}=0.99,0.99,0.99,0.94\right.$, and 0.70 , respectively $)$, indicating a dose-response relationship which began to decay (reach saturation) approximately $12 \mathrm{~h}$ after victorin treatment (Fig. 1B). Therefore, electrolyte leakage at these doses and up to $12 \mathrm{~h}$ after treatment appears to provide a quantitative measure of victorin-mediated cell death.

VIGS was used for silencing a set of plant genes that have known roles in defense signaling to determine whether they serve a function in victorin-mediated cell death. We silenced $N$. benthamiana orthologs of the mitogen-activated-protein (MAP)-kinases WIPK and SIPK; the MAP-kinase kinases (MAPKK) $M E K 1, M E K 2$, and $M A P K K K \alpha$, the protein kinase $A D I 2$; the lipase-like protein $E D S 1$; the NB-LRR $N R C 1$; and $S G T 1, R A R 1$, and HSP90 (members of a chaperon complex), each of which has been implicated in signaling during the HR (Bogdanove and Martin 2000; Calderini et al. 2001; Gabriëls et al. 2007; Liu et al. 2002; Pozo et al. 2004; Seo et al. 2008; Shirasu 2009; Yang et al. 2001; Zhang et al. 2000). We routinely assayed for both victorin sensitivity and cell death induced by the overexpression of the $R P P 8 R$ gene in leaves of plants silenced for individual genes. RPP8 is constitutively active when overexpressed (Luo et al. 2009). By monitoring cell death induced by RPP8 expression, we could compare the signaling requirements for LOV1 to that of a highly homologous protein with known resistance function. Of the genes tested, $N b S G T 1$ was identified to be required for victorin-mediated cell death in $N$. benthamiana (Fig. 2). Leaves transiently expressing $L O V 1$ and $T R X-h 5$ in plants inoculated with the control TRV:GFP construct showed the expected cell death phenotype following victorin treatment (Fig. 2A). In contrast, leaves transiently expressing $L O V 1$ and $T R X$ - $h 5$ from $N b S G T 1$-silenced plants showed no cell death after victorin treatment (Fig. 2A). 
Cell death induced by RPP 8 expression was not affected by silencing NbSGT1 (Fig. 2A). The reduction in visible cell death mediated by victorin correlated with reduced electrolyte leakage. Leaf disks excised from LOV1- or TRX-h5-expressing leaves from plants silenced for $N b S G T 1$ exhibited considerably less electrolyte leakage over an 8-h time period after victorin treatment compared with the control (Fig. 2B). When NbSGT1 was silenced, electrolyte leakage was approximately $10 \%$ of that observed in the positive control $8 \mathrm{~h}$ after victorin treatment (Fig. 2B).

Because SGT1 is a chaperone that can impact the accumulation of R proteins (Azevedo et al. 2006), we wanted to determine whether the reduction in victorin-mediated cell death in $N b S G T 1$-silenced plants was due to a reduced accumulation of LOV1 protein. To monitor the effect of silencing NbSGT1 on
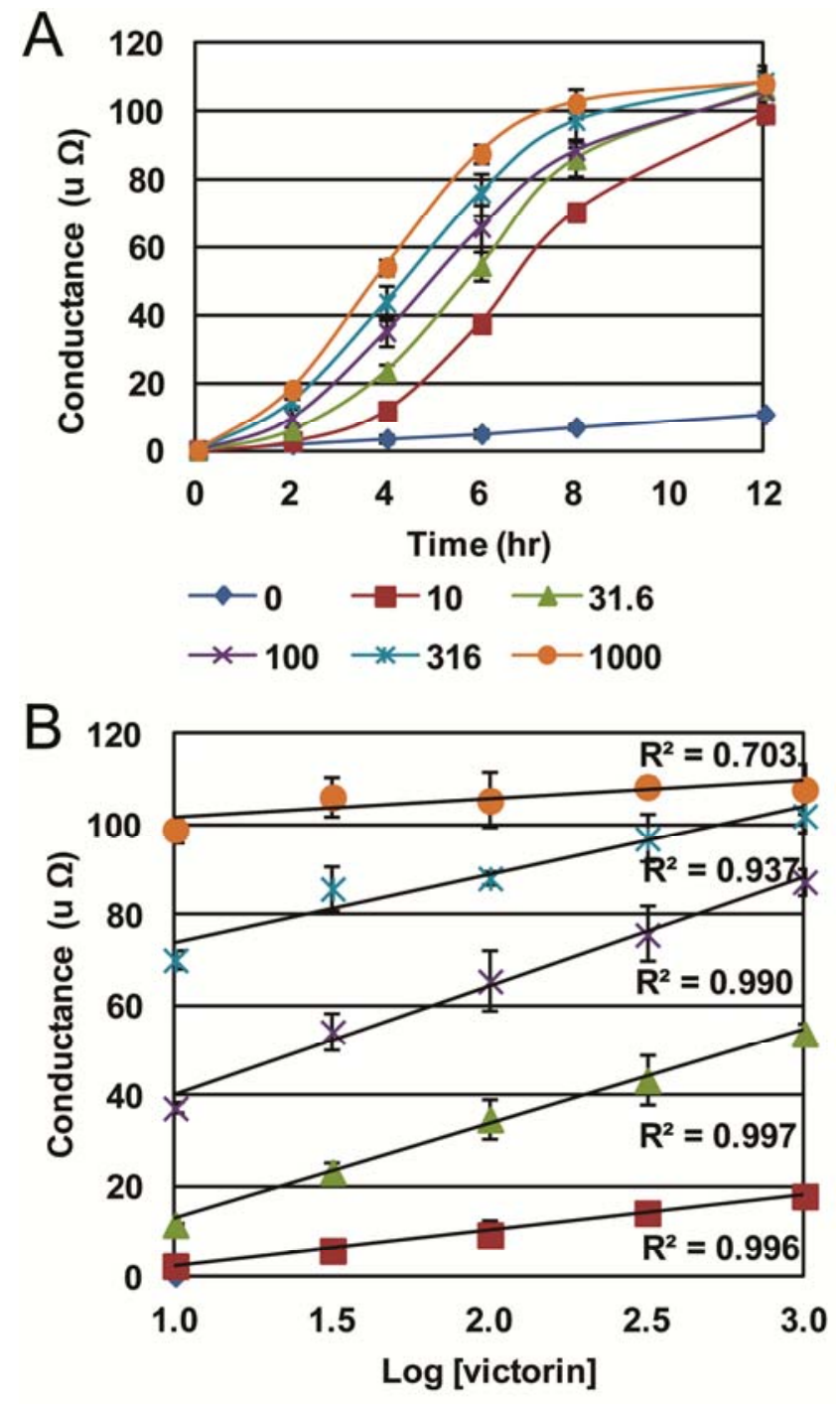

$\square 2 \mathrm{hr} \triangle 4 \mathrm{hr} \times 6 \mathrm{hr} * 8 \mathrm{hr}-12 \mathrm{hr}$

Fig. 1. Victorin elicits electrolyte leakage as a dose-responsive indicator of cell death in Nicotiana benthamiana leaves expressing LOV1 and TRX-h5. Effect of victorin concentration on electrolyte leakage kinetics from leaf disks from leaves of plants expressing Tobacco rattle virus (TRV):GFP, a negative control used for virus-induced gene silencing, and LOVI and $T R X-h 5$. A, Leakage over a 12 -h time-course following treatment with victorin at $0,10,31.6,100,316$, or $1,000 \mathrm{ng} / \mathrm{ml}$. B, Electrolyte leakage increases as a $\log$ dose response to victorin concentration indicating a dose-response relationship for $12 \mathrm{~h}$ after treatment. Means \pm standard error of three samples are plotted and are representative of three independent experiments.
TRX-h5 protein levels, myc-tagged TRX-h5 was expressed. Myc-tagged TRX-h5 is fully functional in conferring victorinmediated cell death when co-expressed with LOV1 (Lorang et al. 2012). Total protein extracts from LOV1- or myc:TRX-h5-
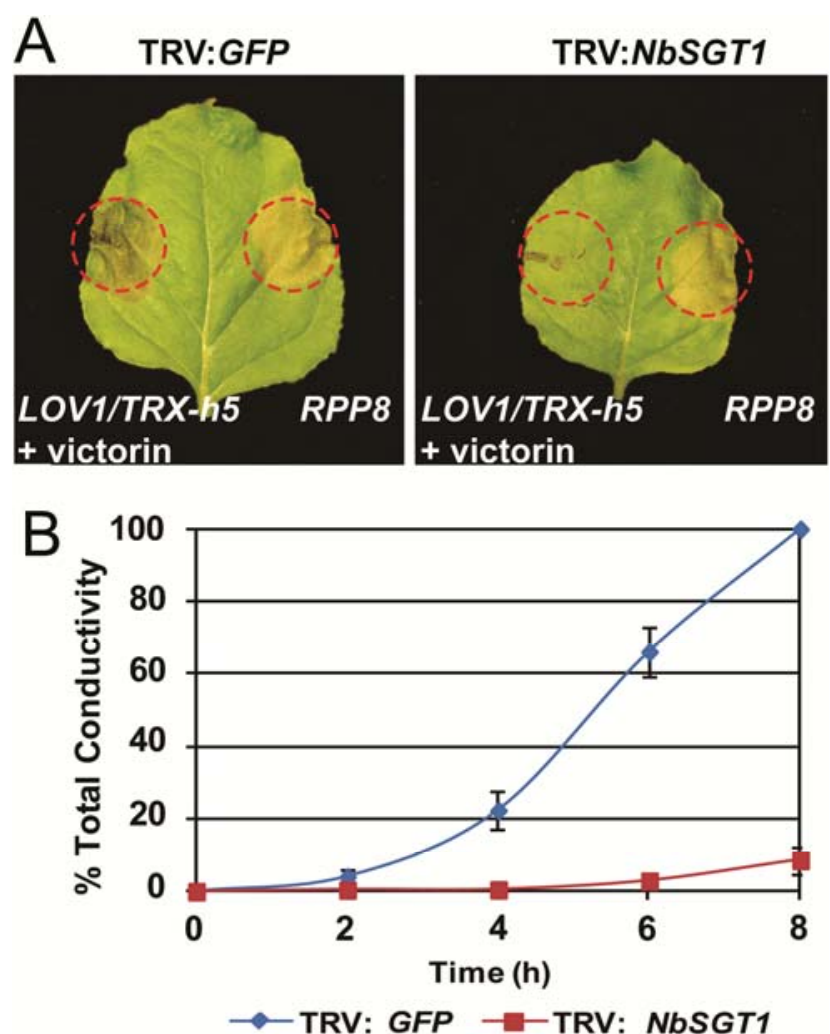

C

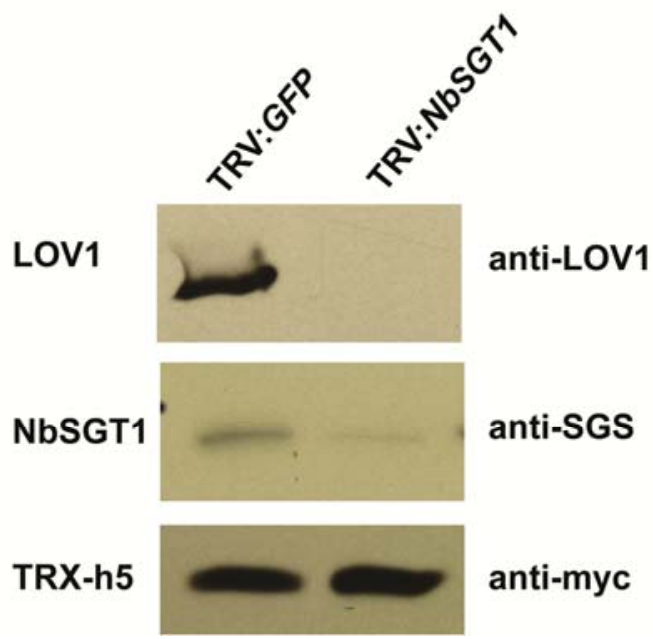

Fig. 2. Victorin-mediated cell death is inhibited by silencing $N b S G T 1$. A, Leaves from plants expressing Tobacco rattle virus (TRV):GFP (control) or TRV:NbSGT1 were inoculated (in region identified by red circles) with Agrobacterium containing constructs to transiently overexpress LOV1 and $T R X-h 5$ or $R P P 8$ (control). At $72 \mathrm{~h}$ after inoculation, $100 \mathrm{ng}$ of victorin was infiltrated into the region expressing LOVI and TRX-h5. Cell death was assessed $24 \mathrm{~h}$ after victorin treatment. B, Electrolyte leakage is reduced in leaves when $N b S G T 1$ is silenced. Electrolyte leakage kinetics were analyzed following victorin treatment at $31.6 \mathrm{ng} / \mathrm{ml}$ of leaf disks from leaves of plants inoculated with TRV:GFP or TRV:NbSGT1 and expressing LOVI and TRX-h5. Conductivity is reported relative to control at $8 \mathrm{~h}$. Means \pm standard error of three independent experiments are plotted. C, NbSGT1 positively regulates LOV1 accumulation. Protein was extracted from leaves of plants inoculated with TRV:GFP (control) or TRV:SGT1 and expressing LOV1 and myc:TRX. Relative amounts of LOV1, myc:TRX-h5, and NbSGT1 were determined by Western blotting with anti-LOV1, anti-myc, and anti-SGS antibodies, respectively. 
expressing leaves silenced for NbSGT1 or expressing TRV: GFP (control) were analyzed by Western blotting. Probing with an antibody raised against the conserved SGS domain of SGT1 (Azevedo et al. 2002) confirmed the depletion of NbSGT1 protein when silencing NbSGT1. This depletion of NbSGT1 correlated with a reduction in LOV1 protein. Levels of mcy: TRX-h5 protein, which serves as an internal control, were not affected (Fig. 2C). In Arabidopsis, there are two SGT1 isoforms, AtSGT1a and AtSGT1b. An Arabidopsis LOV1 genotype containing a mutation in AtSGTIb was previously found to be fully sensitive to victorin (Lorang et al. 2007) but plants having an AtSGTla mutation had not been evaluated for victorin sensitivity. We obtained an AtSGT1a T-DNA insertion mutant (GABI_266H09) and crossed it with a wild-type LOV1 plant. Western blot and insertion analyses indicated that GABI_266H09 is likely a null mutation (Supplementary Fig. S1). We found that plants homozygous for the T-DNA insertion and LOVI were indistinguishable from wild-type plants with regard to victorin sensitivity. Therefore, we concluded that, if SGT1 is required for victorin-mediated cell death in Arabidopsis, AtSGT1a and AtSGT1b likely have redundant functions.

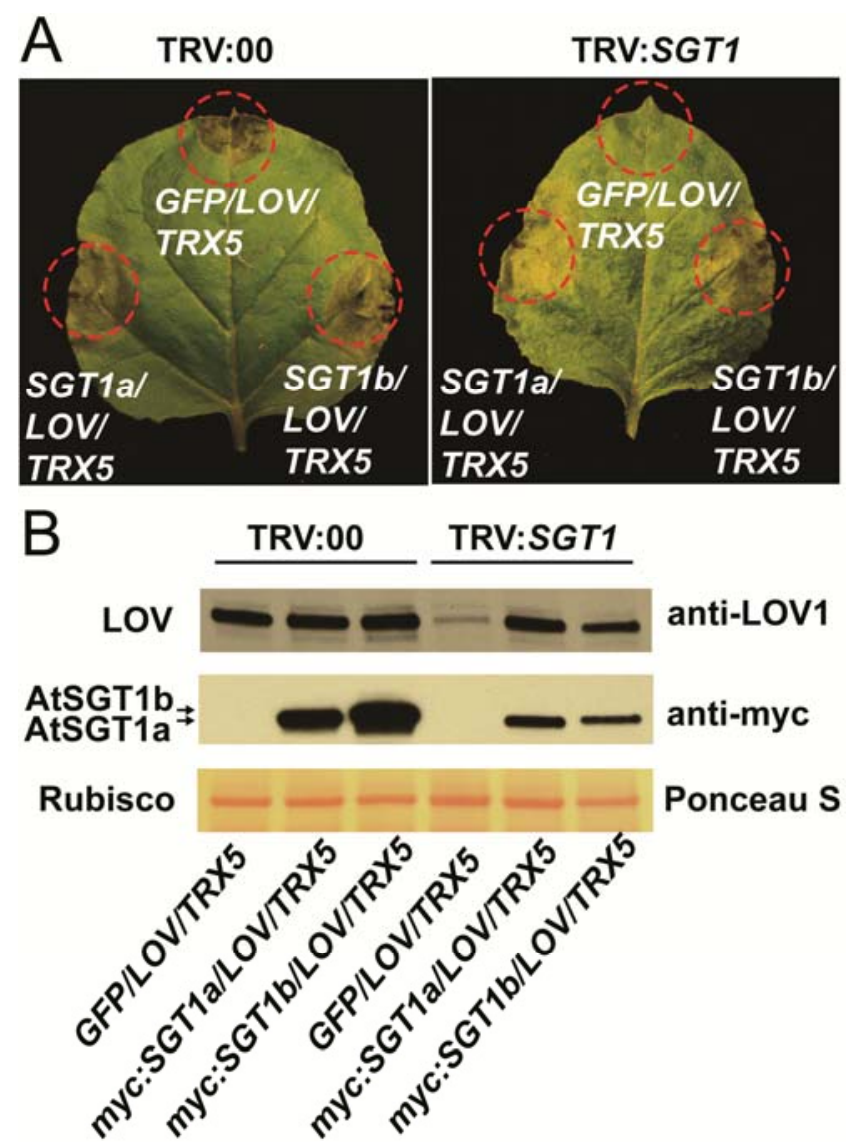

Fig. 3. Transient expression of AtSGT1a or AtSGT1b complements silenced NbSGT1 and restores victorin-mediated cell death. A, Leaves from plants silenced with Tobacco rattle virus (TRV):SGT1 or TRV:00 (empty-vector control) were infiltrated in the areas indicated by red circles with Agrobacterium to overexpress LOV1 (LOV) and TRX-h5 (TRX5) in combination with GFP (control), AtSGT1a, or AtSGT1b. Cell death was assessed $24 \mathrm{~h}$ after victorin treatment at $10 \mu \mathrm{g} / \mathrm{ml}$. B, Relative abundance of LOV1 increases when LOV1 is co-expressed with myc:AtSGT1a or myc:AtSGT1b in leaves from plants silenced with TRV:NbSGT1. Total protein was extracted from leaves of plants silenced with TRV:00 (control) or TRV:SGT1 expressing the indicated constructs. Relative amounts of LOV1, AtSGT1a, and ATSGT1b were determined by Western blotting. Equal loading of the different lanes was confirmed by Ponceau $\mathrm{S}$ staining of rubisco on blot membrane.
Because AtsgtlalAt sgtlb double mutants are embryo lethal (Azevedo et al. 2006), we utilized a heterologous transient complementation assay in $N$. benthamiana (Azevedo et al. 2006) to determine whether either AtSGT1a or AtSGT1b is able to function in victorin-mediated cell death. The ability of AtSGTla or AtSGT1b expression to complement silencing of NbSGT1 and restore victorin sensitivity was tested (Fig. 3). As expected, coexpression of the control GFP with LOVI and TRX-h5 did not complement victorin sensitivity in plants silenced for NbSGT1. Concurrently, co-expression of AtSGT1a or AtSGT1b with LOVI and $T R X-h 5$ had no visible effect on victorin-mediated cell death in plants expressing the empty vector control, TRV:00 (Fig. 3A). In contrast, co-expression of myc:AtSGTla or myc:AtSGT1b with $L O V 1$ and TRX- $h 5$ restored victorin sensitivity in NbSGT1silenced plants (Fig. 3A). Western blot analysis verified the accumulation of myc:AtSGT1a and myc:AtSGT1b protein when expressed in NbSGT1-silenced plants (Fig. 3B). As expected, when LOVI is co-expressed with the GFP control, levels of LOV1 protein are reduced in NbSGT1-silenced plants compared with the control (Fig. 3B). In contrast, when LOV1 is coexpressed with AtSGT1a or AtSGT1b, LOV1 levels in NbSGT1silenced plants are restored to levels similar to that of the unsilenced control (Fig. 3B). These data demonstrate that both AtSGT1a and AtSGT1b have the capacity to function in victorin-mediated cell death and LOV1 accumulation.

\section{A high-throughput VIGS screen identifies several genes involved in victorin-mediated cell death.}

To identify additional genes involved in victorin-mediated cell death, we used VIGS to silence approximately 4,000 genes from an $N$. benthamiana mixed-elicitor cDNA (cNbME) library. The cNbME library was prepared from tissue exposed to the plant pathogens Agrobacterium tumefaciens, $P$. syringae pv. tabaci, and $P$. syringae pv. tomato, and to the abiotic elicitors salicylic acid (SA), jasmonic acid (JA), and ethylene. (Anand et al. 2007). TRV clones (one gene per clone) from the library were individually inoculated into duplicate $N$. benthamiana plants. After silencing, we tested for both victorin sensitivity and cell death induced by the expression of RPP8. For every experiment, VIGS of the non-plant gene, GFP, was used as a negative control for cell death and VIGS of LOVI was used as a positive control for the loss of victorin-mediated cell death (Fig. 4A). Any clones that interfered with victorin-mediated cell death or cell death induced by RPP 8 expression in at least one replicate in the primary screen were subjected to subsequent screenings in triplicate. In these subsequent screens, Agrobacterium carrying a construct to express the GFP reporter was infiltrated to identify and eliminate clones that silenced genes that interfere with transient expression. Four days following Agrobacterium inoculation, GFP fluorescence in the area inoculated was monitored under a UV transilluminator to verify efficient transient expression (Fig. 4A). After four rounds of screening, we identified six clones which reproducibly inhibited both victorin-mediated cell death and cell death induced by RPP8 expression (Fig. 4B). These clones were chosen for further analyses. Five of these six clones produce a mildly chlorotic, silencing phenotype. This phenotype was common in our VIGS screening, and does not affect victorin sensitivity per se (Supplementary Fig. S2).

The inserts in clones TRV:2G9, TRV:4A4, TRV:8D7, TRV:12G1, TRV:38E2, and TRV:40C5 were sequenced to infer gene function. The sequences were used in BLASTN searches of The Gene Index Project (Dana-Farber Cancer Institute [DFCI], Boston) to identify homologous putative expressedsequence tag (EST) contigs in $N$. benthamiana (Table 1). To confirm the DFCI annotation, the matching EST were used in a BLASTX search against The Arabidopsis Information Re- 
source (Columbus, OH, U.S.A.) database (Table 1). The cDNAs in TRV:2G9, TRV:4A4, TRV:8D7, TRV: 12G1, TRV:38E2, and TRV:40C5 correspond to the $N$. benthamiana genes $G O X$, $G D C-T, G L U, G D C-P, G A P B$, and $P H T$, respectively.

The electrolyte leakage assay was used to quantify suppression of victorin-mediated cell death when silencing $G O X$, $G D C-T, G L U, G D C-P, G A P B$, and $P H T$. Leaf disks from plants with these genes silenced, and expressing LOV1 and TRX-h5, exhibited significantly reduced electrolyte leakage after victorin treatment when compared with the control (Fig. 5). Silencing $G O X, G D C-P, G A P B$, and $P H T$ inhibited cell death by approximately $80 \%$ after $8 \mathrm{~h}$ of victorin treatment, and silencing $G L U$ inhibited cell death by approximately $90 \%$ after $8 \mathrm{~h}$ of victorin treatment. Silencing GDC-T inhibited cell death by $60 \%$ after $8 \mathrm{~h}$ of victorin treatment.

Semiquantitative reverse-transcriptase polymerase chain reaction (RT-PCR) was conducted to confirm that VIGS of $G O X$ $G D C-T, G L U, G D C-P, G A P B$, and $P H T$ reduced the abundance of the predicted transcripts (Fig. 6). Transcript abundance corresponding to $G O X, G D C-T, G L U, G D C-P, G A P B$, and $P H T$ was reduced in cDNA prepared from mRNA isolated from plants silenced with the respective constructs compared with the control (Fig. 6A). In all RNA samples, abundance of 18S RNA transcripts was similar and served as an internal control (Fig. 6B).

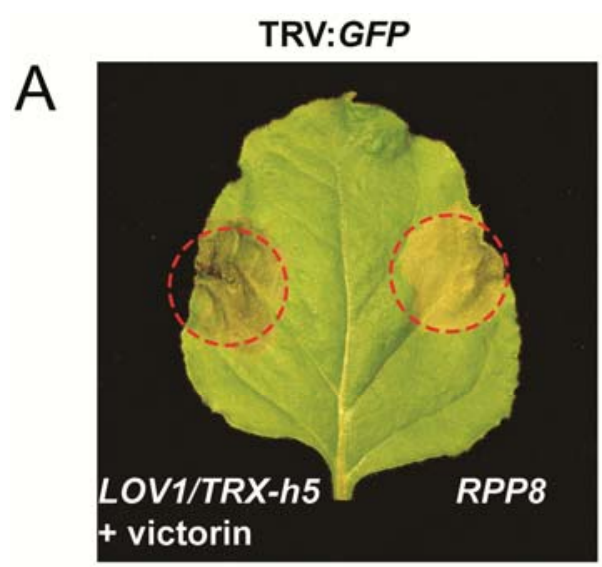

TRV:2G9

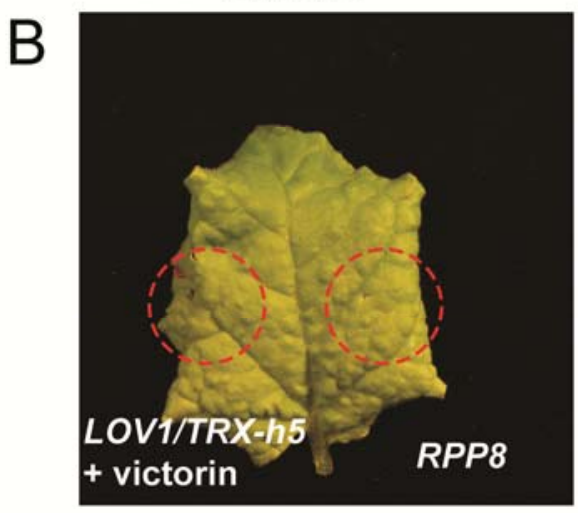

TRV:12G1

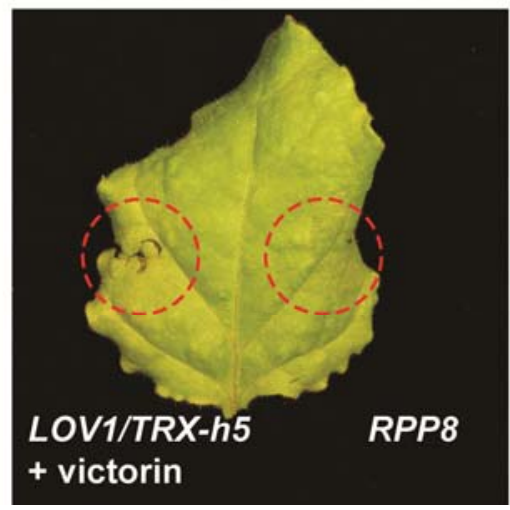

TRV:LOV1

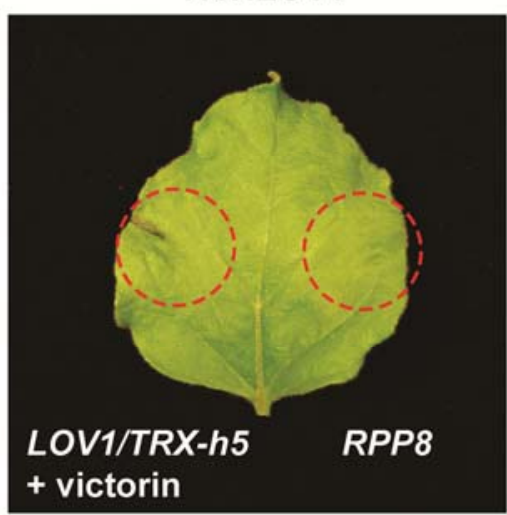

TRV:8D7

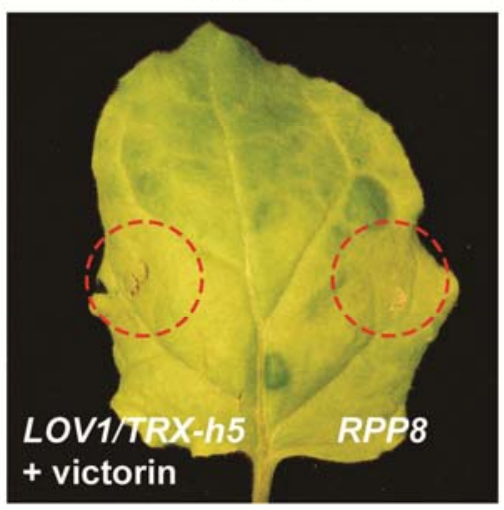

TRV:38E2

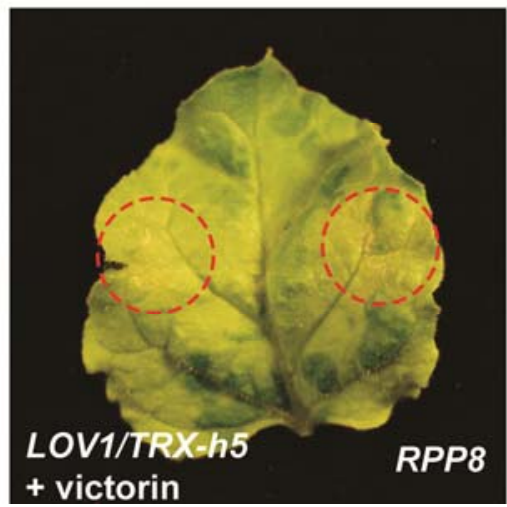

TRV:LOV1

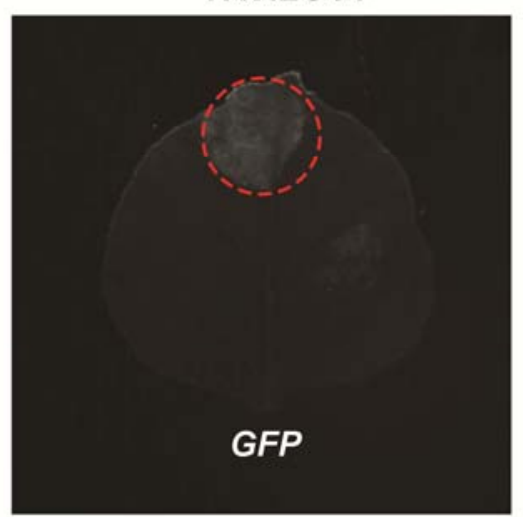

TRV:4A4

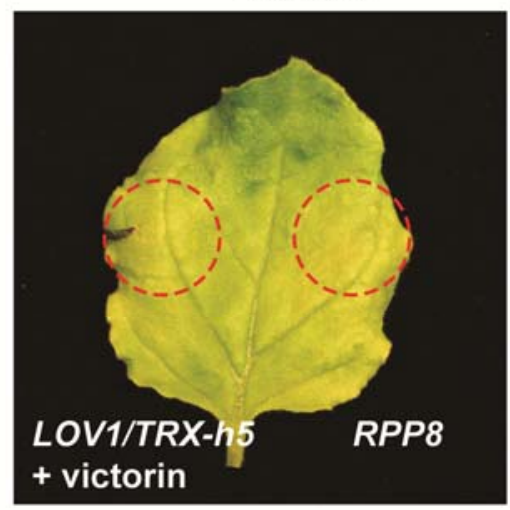

TRV:40C5

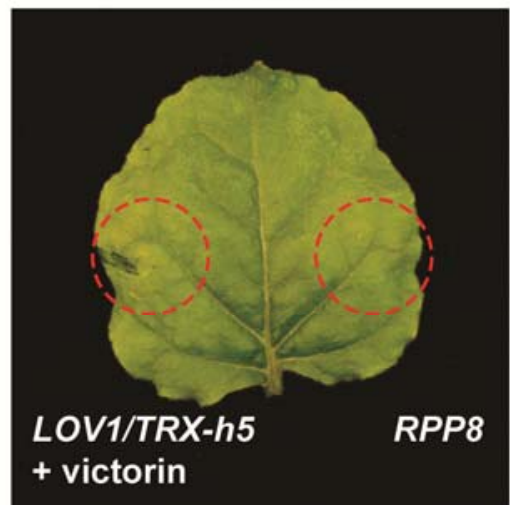

Fig. 4. Virus-induced gene silencing (VIGS)-based identification of cDNA clones that inhibit victorin-mediated, LOV1-dependent cell death and cell death induced by RPP8. A, Controls used in the VIGS screen. Assessment of cell death after VIGS of GFP (negative control), VIGS of LOV1 (positive control), and an example image demonstrating no effect on GFP fluorescence as used to confirm clones tested had no effect on Agrobacterium-mediated transient expression. B, Assessment of cell death in leaves from plants silenced with the clones identified from the screen. Tobacco rattle virus (TRV)-infected plants were infiltrated (in the regions identified by red circles) with Agrobacterium containing constructs to overexpress $L O V 1$ and TRX-h5, or RPP8. At $48 \mathrm{~h}$ after Agrobacterium inoculation, victorin was infiltrated in the region of $L O V 1$ and $T R X-h 5$ expression. Pictures were taken 24 h after victorin treatment. 
VIGS of GOX, GDC-T, GLU, GDC-P, and GAPB affects the PTO-mediated resistance pathway.

To determine whether VIGS of GOX, GDC-T, GLU, GDCP, GAPB, and PHT inhibits other cell death pathways associated with $R$ gene activation, these genes were silenced in $N$. benthamiana expressing PTO and BS2 $R$ genes (Fig. 7). As expected, transient expression of the constitutively active form of PTO (PTOY207D) resulted in cell death in leaves from wildtype $N$. benthamiana plants expressing the TRV:GFP (control) (Fig. 7A). In GOX-, GDC-T-, GLU-, GDC-P-, and GAPBsilenced plants, cell death was absent in regions of leaves expressing PTOY207D (Fig. 7A). PTO-mediated cell death was not inhibited in plants silenced for PHT (Fig. 7A). In contrast, there was no reduction in cell death mediated by the expression of AvrBs2 in BS2-transgenic N. benthamiana plants silenced with any of the constructs (Fig. 7B).

We determined whether the loss of PTO-mediated cell death was accompanied by a reduction of PTO-mediated disease resistance (Fig. 8). GOX, GDC-T, GLU, GDC-P, and GAPB were silenced in transgenic $N$. benthamiana that expressed the PTO $R$ gene (G. Martin, Boyce Thompson Institute, unpublished). As a control for the loss of resistance, PRF (NBLRR required by Pto) was silenced, which is required for PTO-mediated resistance (Salmeron et al. 1996). As additional controls, TRV:GFP was expressed in wild-type and PTO-transgenic $N$. benthamiana. Silenced plants were inoculated at a low concentration $\left(1 \times 10^{4} \mathrm{CFU} / \mathrm{ml}\right)$ by infiltration of either compatible $P$. syrinagae pv. tabaci or incompatible $P$. syrinagae pv. tabaci carrying ArvPto. Bacterial growth was monitored 2 days after inoculation. PTO-mediated resistance was observed by the differential growth of $P$. syrinagae pv. tabaci (avrPto) in TRV:GFP expressing PTO transgenics compared with either PTO transgenics silenced for PRF or the wild type (no PTO) expressing TRV:GFP (Fig. 8A). Growth of $P$. syrinagae pv. tabaci (avrPto) in PTO plants silenced for PRF was similar to wild-type plants expressing the TRV:GFP control, demonstrating effective reduction of PTO-mediated resistance by VIGS (Fig. 8A). An approximate 10 -fold increase in P. syrinagae pv. tabaci (avrPto) growth was observed in PTO plants silenced for GLU compared with PTO plants expressing the control TRV:GFP $(t$ test, $P<0.05)$ (Fig. 8A). There was a moderate but significant fourfold increase in P. syrinagae pv. tabaci (avrPto) growth in PTO plants silenced for GDC-T, GDC-P, and GAPB compared with the controls (analysis of variance [ANOVA], $P<0.05$ ) (Fig. 8A). Growth of P. syrinagae pv. tabaci (avrPto) in PTO plants silenced for GOX was similar to resistant controls (Fig. 8A), even though silencing of this gene has a consistent effect on visible cell death mediated by PTO (Fig. 7). Inconsistent results were obtained when silencing PHT over the course of four independent experiments (data not shown). Growth of compatible P. syrinagae pv. tabaci lacking avrPto was similar in all silenced plants, indicating that the differ- ences seen in the growth of $P$. syrinagae pv. tabaci (avrPto) are specific to the expression of disease resistance (Fig. 8B).

\section{DISCUSSION}

To further characterize the victorin response and clarify its relationship with ETI, we used VIGS to identify genes required for victorin-mediated cell death. By silencing a set of plant genes that have known roles in defense, we identified a requirement for $S G T 1$ in victorin-mediated cell death (Fig. 2). SGT1 is a highly conserved, eukaryotic protein associated with protein complexes involved in multiple processes (Shirasu and Schulze-Lefert 2003). In plants, SGT1 has been shown to be involved in auxin and jasmonate responses (Gray et al. 2003), heat shock tolerance (Noel et al. 2007), and immunity against pathogens (Peart et al. 2002; Seo et al. 2008; Shirasu 2009). Mutation analysis and gene silencing experiments have demonstrated that SGT1 is required for plant defenses conferred by diverse $R$ genes (Austin et al. 2002; Peart et al. 2002). SGT1 is thought to act as a co-chaperone, interacting with the co-chaperonins heat shock protein 90 (HSP90) and required for MLa12 resistance (RAR1) (Takahashi et al. 2003) in a molecular chaperon complex. Thus, SGT1 likely functions in protein folding and stability (Seo et al. 2008; Shirasu 2009). However, HSP90, RAR1, and SGT1 are differentially required for resistance depending on the specific R protein (Seo et al. 2008).

SGT1 is required for steady-state accumulation of NB-LRR disease R proteins such as Rx (Azevedo et al. 2006; Botër et al. 2007) and N (Mestre and Baulcombe 2006), indicating that one-way SGT1 regulates plant resistance function is by maintaining the stability of $\mathrm{R}$ proteins (Azevedo et al. 2006). We show here that silencing $S G T 1$ results in reduced levels of LOV1 when transiently expressed in $N$. benthamiana (Fig. 2), and conclude that SGT1 has a role in maintaining the stability of LOV1. This suggests that SGT1 would positively regulate susceptibility to $C$. victoriae. However, we were unable to test this in our heterologous, transient expression system due to the need to infiltrate Agrobacterium. Notably, SGT1 has been shown to positively regulate disease susceptibility to Botrytis cinerea in $N$. benthamiana (Oirdi and Bouarab 2007). Like $C$. victoriae, $B$. cinerea is a necrotrophic pathogen, which is thought to manipulate defense signaling to promote cell death for pathogenesis.

In Arabidopsis, SGT1 has two isoforms, AtSGT1a and AtSGT1b, each of which are able to function in certain $R$ gene-mediated resistance pathways (Azevedo et al. 2006). Mutations in either AtSGTIa only or AtSGTIb only (Lorang et al. 2007) do not affect victorin sensitivity. Because a sgtla/sgtlb double mutant is lethal in Arabidopsis (Azevedo et al. 2006), we heterologously expressed AtSGTIa and AtSGTIb in N. benthamiana silenced for $N b S G T 1$ and showed that each of these isoforms is able to function in victorin-mediated cell death (Fig. 3). While it is possible that complementation re-

Table 1. Clones and their corresponding gene annotations identified as required for RPP8 and victorin-mediated cell death in a virus-induced gene silencing screen of the cNbME library ${ }^{\mathrm{a}}$

\begin{tabular}{lllllll}
\hline TRV clone & Gene Index ID & E value & Symbol & Arabidopsis homolog & Identity (\%) & Description \\
\hline 2G9 & TC22852 & 6.E-07 & GOX & At3g14420 & 90 & Glycolate oxidase \\
4A4 & CN742595 & 2.E-08 & GDC-T & At1g11860 & 80 & Glycine cleavage T-protein \\
8D7 & TC19485 & 2.E-08 & GLU & AT5G35630 & 92 & Glutamine synthetase 2 \\
12G1 & TC20514 & 1.E-07 & GDC-P & AT4G33010 & 84 & Glycine decarboxylase P-protein 1 \\
38E2 & CN743656 & 1.E-04 & GAPB & AT1G42970 & 85 & Glyceraldehyde-3-phosphate dehydrogenase \\
& & & & & B subunit, chloroplast localized \\
40C5 & TC19080 & 3.E-08 & PHT & AT5G14040 & Phosphate transporter 3, mitochondrial & Pho \\
\hline
\end{tabular}

${ }^{\text {a }}$ Listed are the cDNAs corresponding to the Tobacco rattle virus (TRV) inserts and their predicted gene function.

${ }^{\mathrm{b}}$ Nicotiana benthamiana Gene Index, top BLASTN results.

${ }^{c}$ Top BLASTX results. 
quires overexpression of AtSGT1a or AtSGT1b, these data suggest that the absence of an effect of sgtla or sgtlb mutants on victorin sensitivity in Arabidopsis is likely due to redundant contributions of these genes towards LOV1 stability. The re- quirement for SGT1 by LOV1 suggests that LOV1 expression is regulated similarly to other $\mathrm{R}$ proteins.

Because HSP90 and RAR1 are associated with SGT1, we were interested in their effects on victorin sensitivity and LOV1
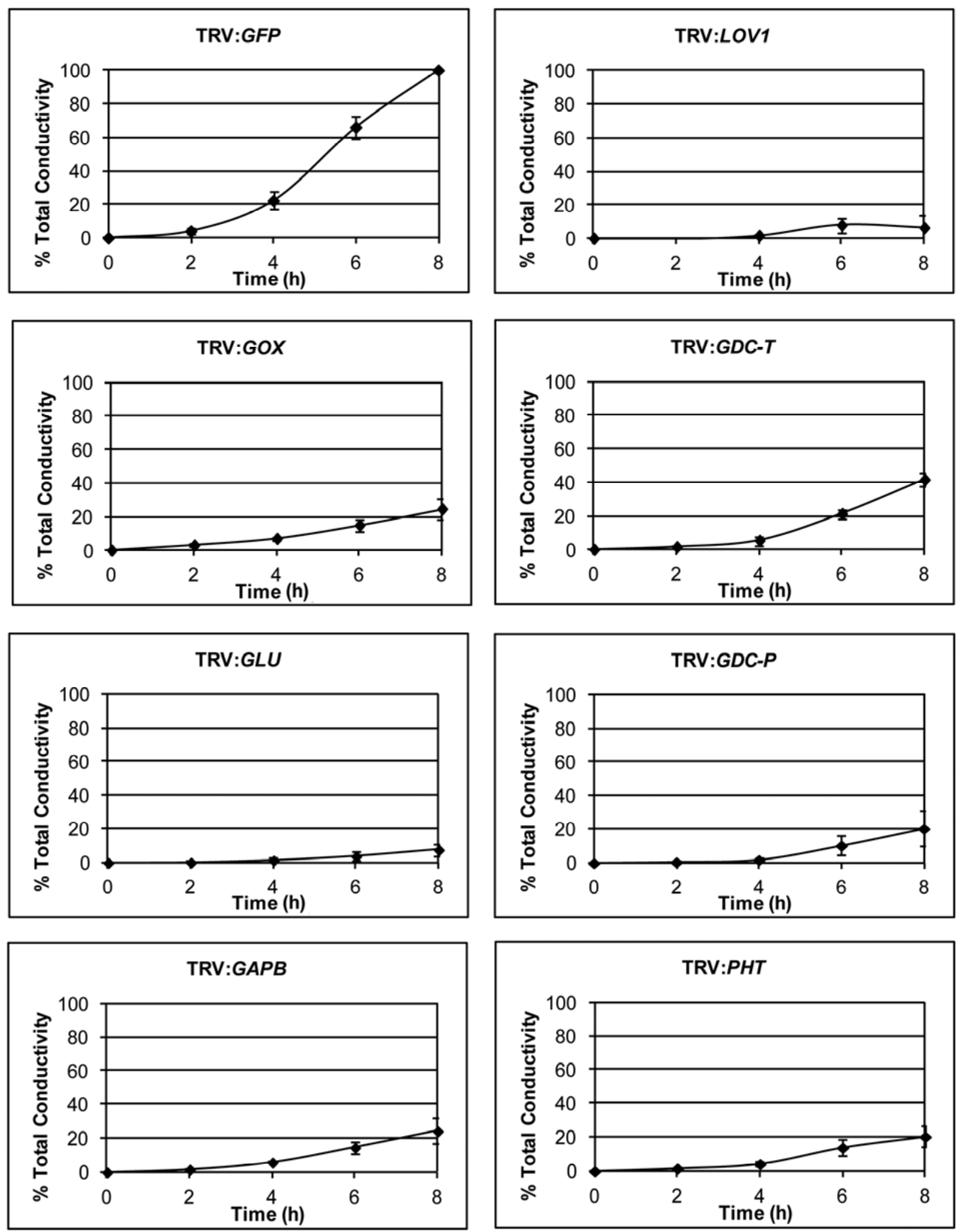

Fig. 5. Virus-induced gene silencing of glycolate oxidase $(G O X)$, the T protein of the glycine decarboxylase complex $(G D C-T)$, glutamine synthetase $(G L U)$, the P protein of GDC $(G D C-P)$, glyceraldehyde 3-phosphate dehydrogenase $(G A P B)$, and mitochondrial phosphate transporter (PHT) inhibits victorin-mediated electrolyte leakage. Kinetics of electrolyte leakage following victorin treatment at $31.6 \mathrm{ng} / \mathrm{ml}$ of leaf disks from $L O V 1$ - or TRX-h5-expressing leaves silenced with controls (Tobacco rattle virus [TRV]:GFP or TRV:LOV1) or clones identified in the genetic screen. Conductivity is reported relative to control at $8 \mathrm{~h}$. Means \pm standard error of three independent experiments are plotted. 
accumulation. A prior study showed that treatment of victorinsensitive Arabidopsis with the HSP90 inhibitor geldanamycin did not reduce sensitivity to victorin (Lorang et al. 2007), however, negative results with geldanamycin cannot exclude a role for HSP90. Geldanamycin treatment did not inhibit the HR mediated by RPM1; nevertheless, HSP90 is important for RPM1 resistance function (Hubert et al. 2003; Takahasi et al. 2003). Interaction between HSP90 and SGT1 is also required for Rx accumulation and function (Botër et al. 2007). A silencing construct, which contained sequence homology to the three $N$. benthamiana HSP90 isoforms identified in N. benthamiana, was designed. However, plants silenced with this construct exhibited significantly reduced Agrobacterium-mediated GFP fluorescence compared with the control, indicating an inhibitory effect on transient expression (data not shown). A role for HSP90 in Agrobacterium-mediated transformation has not been reported in the literature. However HSP90, via its interaction with SGT1 (Takahashi et al. 2003), is associated with the Skp1-Cullin 1-F-box E3 ubiquitin ligase complex (Azevedo et al. 2002; Zhang et al. 2010), which has been implicated in the transfer and integration of bacterial T-DNA during Agrobacterium-mediated transformation (Anand et al. 2012). Thus, we were unable to determine whether HSP90 is required for victorin sensitivity. Future investigations of a possible role for HSP90 in victorin sensitivity should be addressed in a system where transient expression is not required to confer victorin sensitivity. Any approach will likely require gene silencing or mutation of multiple $H S P 90$ alleles, because an HSP90 require-

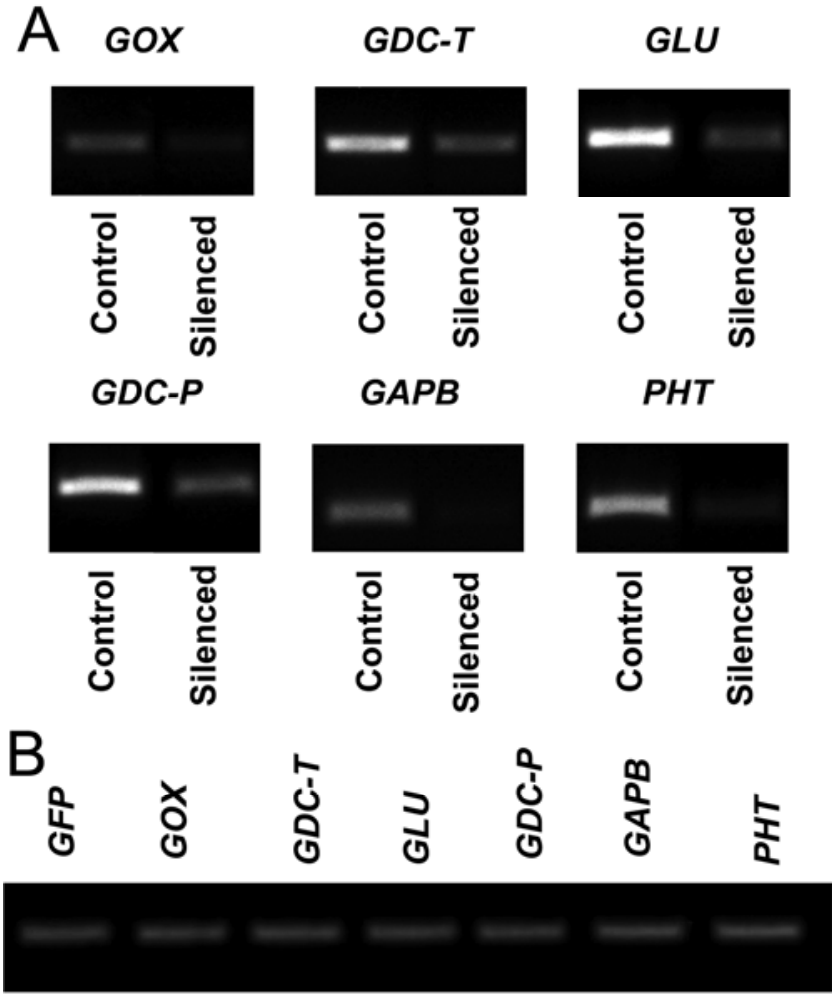

Fig. 6. Semiquantitative polymerase chain reaction (PCR) confirms reduction of transcripts in Tobacco rattle virus (TRV)-silenced plants. A, PCR products amplified with gene-specific primers from cDNA isolated from plants silenced with TRV:GFP (control) or from plants silenced with the specified TRV clones (silenced): glycolate oxidase $(G O X)$, the T protein of the glycine decarboxylase complex $(G D C-T)$, glutamine synthetase $(G L U)$, the P protein of GDC (GDC-P), glyceraldehyde 3-phosphate dehydrogenase $(G A P B)$, and mitochondrial phosphate transporter $(P H T)$. B, PCR products amplified with $18 \mathrm{~S}$ primers (as an internal control) from cDNA isolated from plants silenced with TRV:GFP and specified TRV clones. ment was not identified in a near-saturating EMS mutagenic screen for the loss of victorin sensitivity (Sweat and Wolpert 2007).

The co-chaperone RAR1 can function to enhance the HSP90SGT1 interaction (Botër et al. 2007), and has been shown to positively regulate levels of some $\mathrm{R}$ proteins, including $\mathrm{Rx}$ (Bieri et al. 2004; Tornero et al. 2002). Victorin sensitivity was slightly attenuated in Arabidopsis rarl mutants (Lorang et al. 2007), suggesting that RAR1 may play a role in LOV1 accumulation. However, VIGS of the $N$. benthamiana RAR1 ortholog did not affect victorin sensitivity or LOV1 protein levels in our assays (data not shown). This apparent LOV1 RAR1 independence observed in $N$. benthamiana may be the result of LOV1 overexpression in our heterologous assays, in which minor effects on stability would not be observable.

Another method we used to discover genes required for victorin-mediated cell death was to randomly silence genes from a mixed-elicitor cDNA (cNbME) library with VIGS. With this screen, six genes were identified that, when silenced, consistently inhibited victorin-mediated cell death. These genes included $P H T$, the $\beta$ subunit of photosynthetic $G A P B$, and the

A

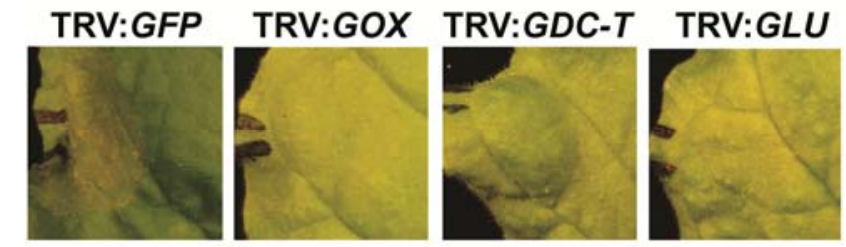

TRV:GDC-P TRV:GAPB TRV:PHT

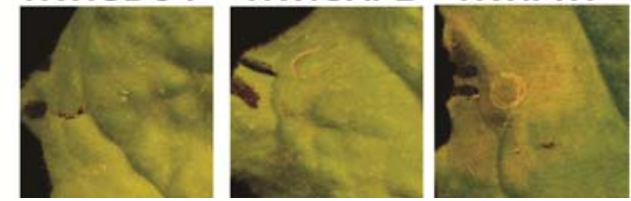

B

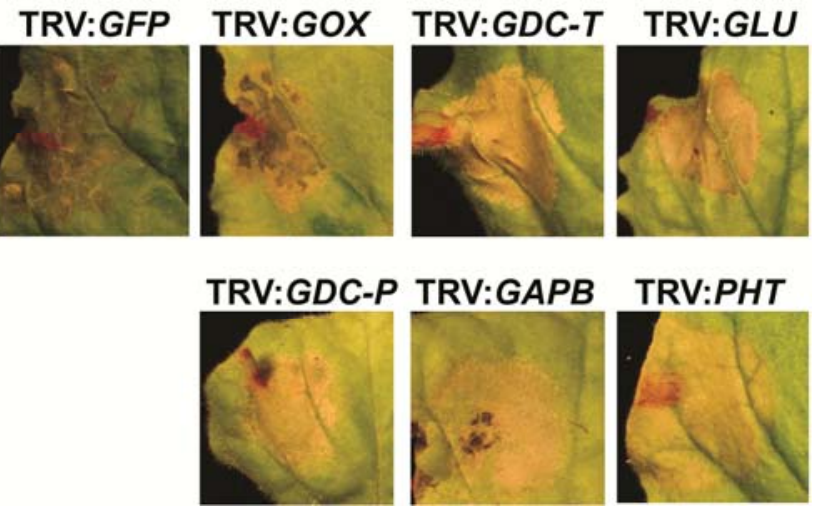

Fig. 7. Virus-induced gene silencing (VIGS) of glycolate oxidase $(G O X)$, the $\mathrm{T}$ protein of the glycine decarboxylase complex $(G D C-T)$, glutamine synthetase $(G L U)$, the P protein of GDC $(G D C-P)$, and glyceraldehyde 3phosphate dehydrogenase $(G A P B)$ (five of the six Tobacco rattle virus [TRV] clones identified in our VIGS screen that inhibit RPP8 and victorinmediated cell death) inhibit cell death mediated by the PTO resistance gene but not the $B S 2$ resistance gene. A, Agrobacterium carrying a construct to express a constitutively-active form of PTO (PTOY207D) was infiltrated into leaves of Nicotiana benthamiana silenced with TRV:GFP (control) and the TRV clones identified from our screen (TRV:GOX, TRV:GDC-T, TRV:GLU, TRV:GDC-P, TRV:GAPB, and TRV:mitochondrial phosphate transporter $[P H T])$. B, Agrobacterium carrying a construct to express $A v r B s 2$ was infiltrated into leaves of $B S 2$-transgenic $N$. benthamiana silenced with the indicated TRV constructs. Cell death was assessed 4 days after infiltration. 
photorespiratory enzymes $G O X, G L U, G D C-P$, and $G D C-T$ (Figs. 4 and 5). Cell death induced by RPP 8 expression was also inhibited in plants silenced for these genes. Significantly, we did not identify any silencing constructs from the cNbME library that inhibited only one of these cell death pathways. This indicates that the cell-death response mediated by the homologous LOV1 and RPP8 proteins are similar. Given that RPP8 confers resistance to Hyaloperonospora arabidopsidis, these results further support the inference that the LOV1-mediated response shares characteristics of a defense response.

Given their implication in NB-LRR-mediated cell death, a role in defense was directly evaluated for the genes that were identified in our screen. Silencing these genes did not affect cell death mediated by the $R$ gene $B S 2$, demonstrating different requirements for different NB-LRR proteins in cell death pathways. However, $P T O$-mediated cell death was compromised in $N$. benthamiana silenced for GOX, GLU, GDC-P, GDC-T, and $G A P B$ (five of the six genes identified) (Fig. 7), thus reinforcing the view that LOV1-mediated cell death is related to that evoked by other R proteins. PTO and BS2 have been demonstrated to utilize different signaling components (Jin et al. 2002); therefore, differences in requirements for cell death mediated by these $R$ genes are not unexpected. PTO-mediated resistance was compromised in plants silenced for $G L U, G D C$ $P, G D C-T$, and $G A P B$, demonstrating a role for these genes in defense. Together, these results support the hypothesis that the victorin response is functionally related to a defense response.

Four of the six genes that were identified (GOX, GLU, $G D C-P$, and $G D C-T$ ) encode photorespiratory enzymes. Photorespiration is a metabolic process in plants that salvages phosphoglycolate, a product of the oxygenase activity of rubisco. Phosphoglycolate is recycled to a Calvin cycle intermediate, phosphoglycerate, in a process which consumes energy and reducing equivalents, and results in is a loss of carbon released as $\mathrm{CO}_{2}$. One of the photorespiratory genes we identified, GOX, encodes GOX and has been previously shown to be involved in cell death and $R$-gene-mediated resistance (Rojas et al. 2012). $G O X$ catalyzes the oxidation of glycolate, derived from phosphoglyate, to glyoxylate, producing hydrogen peroxide in the process. This reaction can be a major source of hydrogen peroxide in photosynthetic cells (Foyer 2009; Noctor et al. 2002). Hydrogen peroxide is an important reactive oxygen species (ROS), which can function as a signaling molecule in defense (Torres et al. 2006). Consistent with our data, Rojas and associates (2012) found that VIGS of GOX inhibited PTO-mediated cell death in $N$. benthamiana, whereas other $R$-gene-mediated cell death pathways tested were unaffected. Rojas and associates (2012) also showed that resistance of Arabidopsis to $P$. syringae pv. tomato mediated by RPM1 and RPS4 is compromised by mutants in members of the GOX family. The Arabidopsis GOX mutants were found to be defective in hydrogen peroxide production after pathogen challenge, independent of NADPH oxidase activity. The timing of this hydrogen peroxide generation followed the second phase of the oxidative bust (Rojas et al. 2012). In N. benthamiana silenced for GOX, $P T O$-mediated resistance against $P$. syringae pv. tabaci was not affected (Fig. 8). This is in contrast to a 10 -fold reduction in RPS4-mediated resistance against $P$. syringae pv. tomato observed by Rojas and associates (2012). However, these differences could be due to differences between the Arabidopsis and $N$. benthamiana pathosystems. In preliminary analyses, we were unable to detect changes in hydrogen peroxide following victorin treatment of LOVI- and TRX-h5-expressing $N$. benthamiana by either staining with 3,3'-diaminobenzidine or chemiluminescence with luminol (data not shown). Due to the transient nature of this signaling molecule, additional analyses will be necessary to address whether the reduction in victorin- mediated cell death in GOX-silenced plants is due to differences in hydrogen peroxide production.

Photorespiratory enzymes other than GOX have been implicated in disease resistance and associated cell death. The photorespiratory enzyme, NADH-dependent hydroxypyruvate reductase (HPR), is the proposed target of P34 (Okinaka et al. 2002), the syringolide receptor that triggers resistance medi-

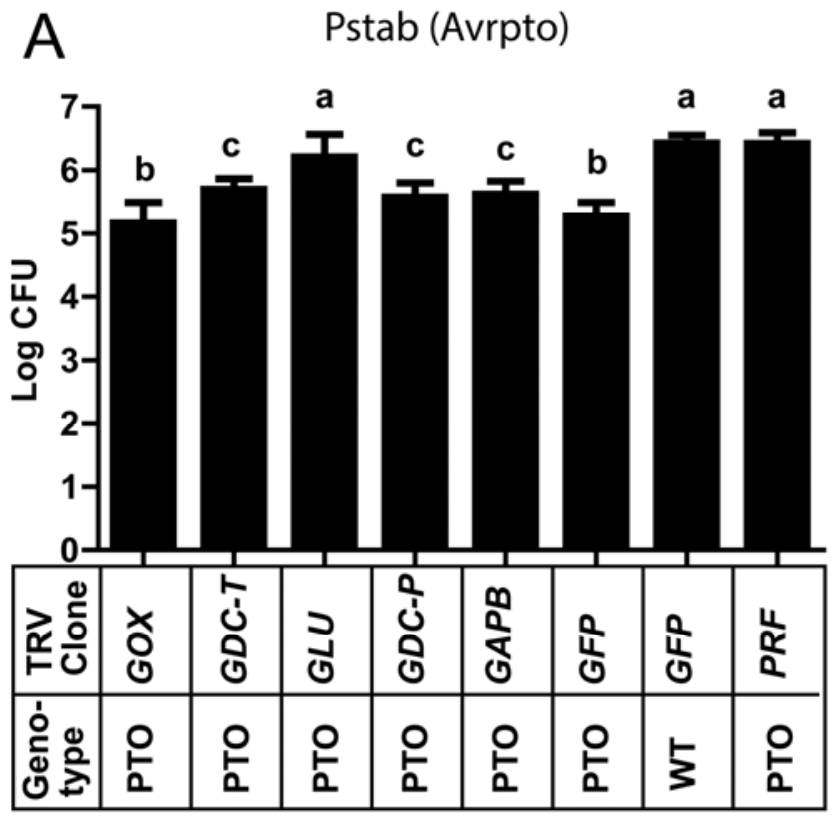

B Pstab (Avrpto)

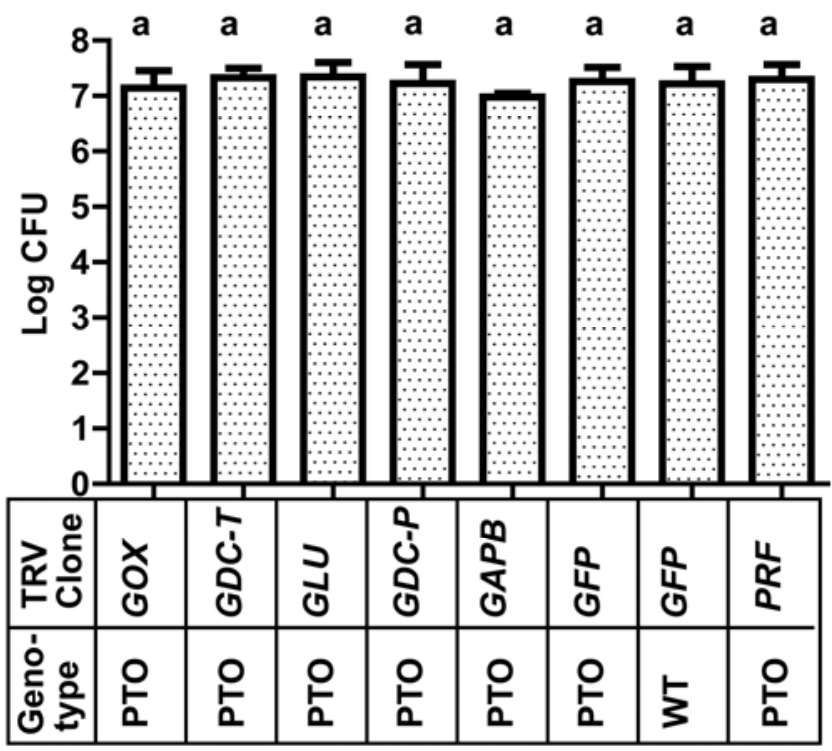

Fig. 8. Virus-induced gene silencing of the $T$ protein of the glycine decarboxylase complex $(G D C-T)$, glutamine synthetase $(G L U)$, the $\mathrm{P}$ protein of GDC (GDC-P), and glyceraldehyde 3-phosphate dehydrogenase (GAPB) compromises resistance mediated by the PTO resistance gene in Nicotiana benthamiana. Pseudomonas syringae pv. tabaci (Pstab) growth 2 days after inoculation of either the $P T O$-transgenic or the $P T O$-transgenic silenced for the identified Tobacco rattle virus (TRV) clones or PRF (control) or wild-type $N$. benthamiana expressing TRV:GFP (control). A, In planta pathogen growth assay to assess virulence of Pstab carrying AvrPto and B, Pstab lacking AvrPto. Error bars represent 95\% confidence limits ( $n=3$ samples) and results are representative of at least three independent experiments. Significantly different means $(P<0.05$, one-way analysis of variance multiple comparison analysis) are indicated by different letters. 
ated by the Rpg4 $R$ gene in soybean (Ji et al. 1998). It was hypothesized that P34 or syringolide binding to HPR inhibits HPR function, leading to Rpg4-mediated cell death (Okinaka et al. 2002) Interestingly, this implies that Rpg4 guards NADHdependent HPR, thereby suggesting that it has a role in defense, a possibility consistent with our findings.

Two genes encoding photorespiratory glyoxylate aminotransferases, when expressed at high levels, confer resistance to the oomycete pathogen Pseudoperonospora cubensis in the plant family Cucurbitaceae (Taler et al. 2004). The enhanced expression of these enzymes correlated with higher GOX activity, which was hypothesized to play a role in the resistance to $P$. cubensis by greater production of hydrogen peroxide (Taler et al. 2004). The two peroxisomal aminotransferases are responsible for the transamination of glyoxylate (formed from the GOX reaction) to glycine (Bourguignon et al. 1999). Glycine is then converted to carbon dioxide, ammonia, and serine by the coupled reaction of the GDC and hydroxymethyltransferase in the mitochondria.

Two components of the GDC (GDC-P and GDC-T) were identified in our screen. Notably, GDC-P was the first hypothesized target of victorin because victorin bound GDC-P only in oat genotypes that are victorin sensitive (Wolpert and Macko 1989). This interaction was hypothesized to play a role in victorin's mode of action, because binding apparently inhibits glycine decarboxylase activity (Navarre and Wolpert 1995). It is now clear that the GDC is not the primary site of action for victorin. Victorin binding to GDC-P in susceptible oat occurs after the initiation of cell death when victorin gains access to the mitochondria, likely through induction of an MPT, an early event in some forms of PCD (Curtis and Wolpert 2002, 2004). In Arabidopsis, the NB-LRR protein, LOV1, conforms to the "guard model" of R protein function and triggers cell death when victorin binds to the guardee, TRX-h5 (Lorang et al. 2007; Lorang et al. 2012). In oat, victorin sensitivity and Victoria blight susceptibility are also associated with an $R$ gene (Mayama et al. 1995; Rines and Luke 1985) and physiological responses mediated by victorin in oat are similar to those of Arabidopsis (Wolpert et al. 2011). Therefore, the mechanism of victorin sensitivity is likely conserved between oat and Arabidopsis and, thus, involves $R$ gene activation. Regardless, a role for the GDC has been implicated in disease resistance. The GDC has been implicated in the HR evoked by harpin, an elicitor produced by the plant pathogen Erwinia amylovora. Harpin leads to inhibition of the GDC by Snitrosoglutathione (Palmieri et al. 2010). It was hypothesized that the GDC regulates ROS production in the mitochondria during the defense response (Palmieri et al. 2010). Our results implicate a positive role for the GDC in the HR and defense. Therefore, binding to the GDC remains a possible effector function for victorin.

It is unclear how VIGS of $G O X, G L U, G D C-P$, and $G D C-T$ suppresses victorin- and $R P P 8$-mediated cell death or cell death and resistance mediated by PTO. Notably, victorinmediated symptom development has been shown to be significantly delayed under environmental conditions that limit photorespiration (Navarre and Wolpert 1999b). Interestingly, GLU catalyzes the rate-limiting step in photorespiration (Kozaki and Takeba 1996). The greatest suppression of victorin-mediated cell death was observed in plants silenced for $G L U$ compared with the other genes identified in our screen (Fig. 5). In addition, the greatest reduction in $P T O$-mediated resistance was observed in plants silenced for $G L U$ compared with the other genes identified in our screen (Fig. 8). This trend could indicate that the effects that were observed are due to changes in the rates of photorespiration after gene silencing. Pleiotrophic effects on photosynthesis should also be considered. Photorespiration operates alongside photosynthesis, linking the rates of photorespiration and photosynthetic metabolism (Kangasjarvi et al. 2012). RNAi inhibition of GOX in rice revealed a direct relationship between GOX activity and photosynthetic rate (Xu et al. 2009). GOX inhibition resulted in a decrease in photosynthetic rate in a linear relationship, demonstrating how changes in photorespiratory enzyme activity could affect primary metabolism (Xu et al. 2009). Photosynthesis could impact cell death and defense by photoproduced ROS or by affecting energy or metabolites required for induction of defense (Bolton et al. 2009; Swarbrick et al. 2006). However, victorin-mediated symptom development was reduced in sensitive oat leaves incubated under elevated $\mathrm{CO}_{2}$ concentrations, a condition that decreases photorespiration without decreasing photosynthesis (Navarre and Wolpert 1999b). This suggests that changes in photorespiratory activity, not photosynthesis, impact victorin-mediated cell death.

Silencing the $\beta$ subunit of photosynthetic $G A P B$ was found to suppress victorin- and RPP8-mediated cell death and cell death and resistance conferred by PTO, providing evidence that the metabolic state can affect symptom development and disease resistance. GAPB catalyzes a reducing step of the Calvin cycle for $\mathrm{CO}_{2}$ fixation and, therefore, is directly involved in metabolism by its role in photosynthesis. Photosynthetic $G A P B$ may also play a signaling role as a mediator of ROS signaling. Photosynthetic $G A P B$ is subject to redox regulation by glutathionylation and hydrogen peroxide (Zaffagnini et al. 2007,2012 ). In addition to regulating enzyme activity, oxidative modification of $G A P B$ is proposed to cause structural changes that change the proteins the enzyme interacts with, as has been shown in animals (Besson-Bard et al. 2008; Hwang et al. 2009; Kim et al. 2003).

In our screen, a mitochondrial phosphate transporter (PHT) was implicated as involved in victorin-mediated cell death and cell death induced by RPP8 expression. PHT catalyzes proton co-transport of phosphate into the mitochondrial matrix. The phosphate transported into the matrix is used for ATP synthesis via oxidative phosphorylation. Recent evidence suggests that, in animal cells, mitochondrial phosphate transporter is a component of the mitochondria permeability transition pore and is involved in the regulation of pore formation (Leung and Halestrap 2008; Varanyuwatana and Halestrap 2012). The MPT is considered an early and essential step of apoptosis. Victorin has been shown to induce an MPT in victorin-sensitive oat, which likely influences the cell death response (Curtis and Wolpert 2002, 2004). The MPT has been shown to play a role in cell death in plants, including Arabidopsis (Arpagaus et al. 2002; Scott and Logan 2008; Tiwari et al. 2002), demonstrating that this mechanism is likely conserved. We have also observed an inhibition of victorin-mediated cell death in N. benthamiana when treated with cyclosporine, an inhibitor of MPT pore opening (data not shown). The phosphate transporter that was identified in $N$. benthamiana is homologous to a family of three phosphate transporters in Arabidopsis, one of which has been confirmed to be localized in the mitochondria in vivo (Aken et al. 2009). Further characterization is necessary to determine whether the PHT identified has a role in the MPT or if the suppression that was observed in victorin-mediated cell death is due to its other roles.

From our screen of approximately 4,000 genes, six genes were identified that are involved in victorin-mediated cell death and cell death induced by RPPS expression. Certain aspects of our screen may have affected the number and types of genes identified. The cNbME library used for screening was derived from leaf tissues exposed to a variety of elicitors and not specifically LOV1- or RPP8-mediated cell death. The abiotic elicitors were SA, JA, and ethylene, and the biotic elicitors PTO/AvrPto-mediated HR, Pseudomonas syringe pv. tomato 
T1-mediated nonhost HR, and disease caused by $P$. syringe pv. tabaci (Anand et al. 2007). Therefore, it is not surprising that some of the genes identified inhibit PTO-mediated cell death, because this was one of the elicitors used for library preparation. The absence of an effect on LOVI- and RPPS-mediated cell death from silencing NRC1, MAPKKK, MEK1, MEK2, $W I P K, S I P K$, and $A D I 2$ (data not shown), which are signaling components required for $P T O$-mediated resistance and cell death, indicates differences between these pathways (Gabriels et al. 2007; Pozo et al. 2004). Also, victorin-mediated cell death and RPP8 function do not require SA or JA signaling components (Eulgem et al. 2004; Lorang et al. 2007), two out of the three abiotic elicitors used for library preparation. Therefore, it is possible that cDNAs in the cNbME library were not enriched for genes involved in signaling pathways for LOV1or RPP8-mediated cell death. In addition, our screen was not saturating, because only 4,000 of an estimated 18,000 genes expressed in $N$. benthamiana (Goodin et al. 2008) were screened. Therefore, it is likely that further components of victorin-mediated cell death could be identified with VIGS.

In summary, our results provide evidence that the victorin response mediated by LOV1 is functionally similar to a resistance response. We found that SGT1, a common modulator of $\mathrm{R}$ protein function, regulates victorin-mediated cell death by maintaining the stability of LOV1. Six genes were identified in a screen of a cNbME library that, when silenced, inhibit both LOV1- and RPP8-mediated cell death, thus suggesting that LOV1 shares functions in common with the closely related $\mathrm{R}$ protein RPP8. In addition, silencing most of these genes inhibited both cell death and resistance mediated by the PTO R protein. These findings, coupled with the genetic association of victorin sensitivity with the $P c 2$ rust $R$ gene in oat (Luke et al. 1966; Mayama et al. 1995; Rines and Luke 1985; Welsh et al. 1954) and our recent finding that the interaction of LOV1, TRX-h5, and victorin recapitulates the guard mechanism for $\mathrm{R}$ protein activation (Lorang et al. 2012), strongly suggest that $C$. victoriae exploits $R$-gene mediated defense for virulence and disease susceptibility.

\section{MATERIALS AND METHODS}

\section{Plant material and bacterial strains.}

$N$. benthamiana or transgenic $N$. benthamiana carrying the PTO (G. Martin, unpublished) or BS2 (Leister et al. 2005) $R$ genes were grown in $3 \frac{1}{4}$-in. pots at $25^{\circ} \mathrm{C}$ in a growth chamber under a cycle of $16 \mathrm{~h}$ of light and $8 \mathrm{~h}$ of darkness. The Arabidopsis thaliana T-DNA insertion mutant (GK_266H09) was obtained from The Ohio State Arabidopsis Biological Resource Center (ABRC). Plants were screened for presence of the TDNA insertion with the forward primer 5 '-CTATCACGCCGA GTGAATCC- $3^{\prime}$ and the reverse primer $5^{\prime}$-TATCTGGGAATG GCGAAATC-3', and screened for the absence of the T-DNA insertion with the forward primer $5^{\prime}$-CTATCACGCCGAGTG AATCC-3' and reverse primer 5'-GTGCCATTGAGTTGGG TTCT- $3^{\prime}$. A homozygote containing the T-DNA insertion was crossed into COL-LOV, a victorin-sensitive line that is nearisogenic to Col-4 (Lorang et al. 2007). F2 plants homozygous for the insertion mutation were screened for the presence of the LOVI gene using the 3571 simple sequence length polymorphism marker (forward 5'-GTGGTGACCTCTCCCT CAAA-3' and reverse 5'-CCCACTTCACCGTTTCTCTC-3') as previously described (Lorang et al. 2007).

Agrobacterium tumefaciens strain GV2260 was used for VIGS and transient expression. Agrobacterium was cultured in Luria-Bertani (LB) media; resuspended in $10 \mathrm{mM}, \mathrm{MES}, \mathrm{pH}$ $5.2(10 \mathrm{mM} \mathrm{MgCl}$ and $150 \mu \mathrm{M}$ acetosyringone) to the indicated optical densities (ODs); and incubated for $3 \mathrm{~h}$ before syringe infiltration. $P$. syringae pv. tabaci isolate 11528 was obtained from J. Chang, Oregon State University (Corvallis, U.S.A.). P. syrinagae pv. tabaci isolate 11528 containing AvrPto (plasmid pPtDC38) (Ronald et al. 1992) was obtained from B. Staskawicz at University California, Berkley (Berkley, U.S.A.) P. syringae pv. tabaci strains were cultured in King's medium B (King et al. 1954).

\section{TRV vectors and derivatives.}

The vectors pTRV1 and Gateway-ready pTRV2 (Liu et al. 2002) and the pTRV2:cNbME library in A. tumefaciens (Anand et al. 2007) were kindly provided by K. Mysore (The Samuel Roberts Noble Foundation, Ardmore, OK, U.S.A.). A. tumefaciens containing the pTRV2 derivatives $M E K 1, M E K 2$, $M A P K K K \alpha, E D S 1, N R C 1$, and $S G T 1$ were obtained from G. Martin (The Boyce Thompson Institute, Ithaca, NY, U.S.A.). For TRV:GFP, TRV:RARl, and TRV:HSP90, fragments corresponding to GFP, RARl, and HSP90 were amplified by PCR, cloned into pENTR/D-TOPO (Life Technologies, Eugene, OR, U.S.A.), and subsequently recombined into Gateway-ready pTRV2 with Gateway LR clonase II enzyme mix (Life Technologies). A 535-bp fragment of GFP was amplified from Pearlygate 103 (Earley et al. 2006) with the forward primer $5^{\prime}$ CACCAGTGGAGAGGGTGAAGGTGA-3' ${ }^{\prime}$ and the reverse primer 5'-AAAGGGCAGATTGTGTGGAC-3'. A 508-bp fragment of HSP90 was amplified from cDNA isolated from $N$. benthamiana with the forward primer 5'-CACCGATCCTGAA GGTTATTCGCA-3' and the reverse primer 5'-CAAGCTTGA GACCTTCCTTG-3'. A 560-bp fragment of RAR1 was amplified from cDNA isolated from $N$. benthamiana with the forward primer 5'-CACCCCAGAGGATCGGGTTGCAACGCC AC- $3^{\prime}$ and the reverse primer $5^{\prime}$-TTTCCATCCTCTCATCCG GT-3'. For TRV:LOV1, LOV1 was recombined from pENTR: LOV1 (Lorang et al. 2012) into pTRV2. The resulting pTRV2 derivatives were transformed into A. tumefaciens. For pTRV:00, empty Gateway-ready pTRV2 was transformed into A. tumefaciens.

\section{VIGS.}

Agrobacterium infiltration for VIGS in N. benthamiana was done by the toothpick method (Anand et al. 2007). Briefly, individual Agrobacterium pTRV2 clones, which contain the fragment of the gene to be silenced, were grown on LB agar. Agrobacterium containing pTRV1 (Liu et al. 2002) at an OD at $600 \mathrm{~nm}\left(\mathrm{OD}_{600}\right)=0.9$ was infiltrated in the second or third true leaf of 3-week-old $N$. benthamiana. Then, a toothpick was used to inoculate the individual TRV2 clones into the same region in which TRV1 was infiltrated. The plants were grown for at least 2 weeks before they were used for assays.

\section{Cell death assays.}

To assay for victorin-mediated cell death, Agrobacterium samples carrying 35S:LOV1 (Lorang et al. 2012) and 35S: $T R X-h 5$ (Sweat and Wolpert 2007) diluted to $\mathrm{OD}_{600}=0.5$ were mixed in equal volumes and syringe infiltrated into fully expanded leaves of silenced $N$. benthamiana. Victorin (100 $\mathrm{ng} / \mathrm{ml}$ ), purified as described previously (Macko et al. 1985; Wolpert et al. 1985) and diluted in water, was infiltrated $48 \mathrm{~h}$ after Agrobacterium inoculation. Cell death was visually assessed $24 \mathrm{~h}$ after victorin infiltration. For complementation of NbSGT1 silencing, Agrobacterium samples carrying pBIN61: myc: AtSGT1a, pBIN61:mycAtSGT1b (Kadota et al. 2008) or PSLJ:GFP diluted to $\mathrm{OD}_{600}=0.5$ were mixed with Agrobac terium carrying $35 \mathrm{~S}: L O V$ and $35 \mathrm{~S}: T R X-h 5$ at $\mathrm{OD}_{600}=0.5$ in equal volumes. Victorin $(10 \mu \mathrm{g} / \mathrm{ml})$ was infiltrated $48 \mathrm{~h}$ after Agrobacterium infiltration. Cell death was visually assessed $24 \mathrm{~h}$ after victorin treatment. 
To assay for cell death induced by RPP 8 expression, silenced leaves were infiltrated with Agrobacterium carrying 35S:RPP8 diluted to $\mathrm{OD}_{600}=0.5$, and cell death was monitored 4 days after Agrobacterium infiltration. 35S:RPP8 was constructed by PCR amplification of RPP8 from pBAR1:RPP8 (McDowell et al. 1998 ) with the primers 5'-TATTAGCGGCCGCATGGCTG AAGCATTTGTGTCG-3' and 5'-TTATTAGCGGCCGCTCCT CAGCCAAGAGATTGGT-3' and subcloning into pENTR/DTOPO (Life Technologies). The resulting clone was recombined into pEarlyGate100 (Earley et al. 2006) with LR clonase (Life Technologies).

PTO-mediated cell death was assayed by infiltrating Agrobacterium containing 35S:PTOY207D (Rathjen et al. 1999) diluted to a final $\mathrm{OD}_{600}=0.4$ into fully expanded leaves from silenced $N$. benthamiana. Cell death was visually monitored 4 days after Agrobacterium infiltration. For BS2-mediated cell death, fully expanded leaves from silenced $B S 2$-transgenic $N$. benthamiana (Leister et al. 2005) were infiltrated with Agrobacterium containing 35S:AvrBs2 (Leister et al. 2005) diluted to $\mathrm{OD}_{600}=0.4$. Cell death was visually monitored 4 days after Agrobacterium infiltration.

\section{Electrolyte leakage assay.}

Fully expanded leaves from silenced plants were infiltrated with Agrobacterium carrying 35S:LOV1 and 35S:TRX5 diluted to $\mathrm{OD}_{600}=0.5$ and mixed in equal volumes. At $48 \mathrm{~h}$ after Agrobacterium infiltration, 36 4-mm leaf disks were excised from three plants silenced for each clone. The 36 disks were pooled, rinsed in $100 \mathrm{ml}$ of deionized water for $30 \mathrm{~min}$, then divided into six sets of 6 and placed into a 24-well multiwell plate. Three sets were treated with victorin at $31.6 \mathrm{ng} / \mathrm{ml}$ and three sets were treated with water, each in a final volume of $2.5 \mathrm{ml}$. For each time-point, "total conductivity" is the conductivity with water treatment subtracted from the conductivity from victorin treatment. Electrolyte leakage is expressed as the percentage of total conductivity elicited for control (TRV:GFP) at $8 \mathrm{~h}$.

\section{Semiquantitative RT-PCR to analyze gene expression.}

Total RNA was extracted from three silenced plants using a Qiagen RNeasy plant mini kit (Germantown, MD, U.S.A.), including an RNase-free DNase treatment step (Qiagen). Firststrand cDNA was synthesized with $500 \mathrm{ng}$ of total RNA, oligo $\mathrm{d}(\mathrm{T})$ primer, and Superscript III reverse transcriptase (Life Technologies). cDNA was amplified by PCR with GoTaq DNA Polymerase (Promega, Madison, WI, U.S.A.) with primers specific for the candidate cDNAs and the $18 \mathrm{~S}$ ribosomal gene as an internal control (Supplementary Table S1). At least one primer of each pair was designed to anneal outside the region targeted for silencing to ensure that the gene of interest was silenced. PCR products were resolved in 1\% agarose gels and the number of cycles was optimized for each transcript. For 18S, GOX, GDC-T, GLU, GDC-P, GAPB, and PHT, 20, 20, 30, $35,35,35$, and 30 cycles were used, respectively.

\section{Protein analysis.}

Protein extracts were prepared by grinding leaf tissue in sodium dodecyl sulfate (SDS) buffer (0.625 Tris, $\mathrm{pH} 6.8 ; 2 \%$ SDS; and 5\% $\beta$-mercaptoethanol). For $N$. benthamiana protein samples, $0.8 \mathrm{~cm}^{2}$ of tissue was ground in $125 \mu \mathrm{l}$. For Arabidopsis, $0.5 \mathrm{~cm}^{2}$ tissue was ground in $125 \mu \mathrm{l}$. Each sample (30 $\mu \mathrm{l}$ ) was loaded onto a 4 to $15 \%$ SDS-polyacrylamide gel (BioRad, Hercules, CA, U.S.A.) and transferred onto Protran nitrocellulose membrane with a $0.2-\mu \mathrm{m}$ pore size (Whatman Schleicher and Schuell, Dassel, Germany). Membranes were blocked in 5\% skim milk powder in $25 \mathrm{mM}$ Tris- $\mathrm{HCl}(\mathrm{pH} 7.5)$, $150 \mathrm{mM} \mathrm{NaCl}$, and $0.1 \%$ Tween-20. Mouse anti-myc-HRP antibody (Life Technologies) was used at a 1:5,000 dilution. Rabbit anti-LOV1 antibody (Lorang et al. 2012) was used at a 1:4,000 dilution. Rabbit anti-SGS antibody (Azevedo et al. 2002) was used at a 1:7,500 dilution. For membranes probed with anti-LOV1 or anti-SGS, goat anti-rabbit HRP conjugate at a 1:10,000 dilution was used as a secondary antibody. Proteins were visualized with ECL chemiluminescent substrate (Life Technologies).

\section{Monitoring of bacterial disease on plants.}

To measure in planta bacterial growth, fully expanded leaves from silenced plants were syringe inoculated with $P$. syrinagae pv. tabaci strains diluted to $10^{4} \mathrm{CFU} / \mathrm{ml}$ in $10 \mathrm{mM} \mathrm{MgCl}_{2}$. Two days following inoculation, nine $1.5-\mathrm{cm}^{2}$ leaf disks were excised from three inoculated leaves of each treatment. The nine discs were divided into three sets of three and were ground in $10 \mathrm{mM} \mathrm{MgCl}_{2}$. The bacterial populations in the leaves were determined by plating serial dilutions on $\mathrm{KMB}$ supplemented with rifampicin at $100 \mathrm{mg} /$ liter. Colonies were counted after $48 \mathrm{~h}$ of growth at $28^{\circ} \mathrm{C}$. All bacterial growth assays were repeated at least three times. Bacterial populations were log-transformed and a one-way ANOVA (Tukey's test) or an unpaired two-tailed $t$ test was used for statistical analysis.

\section{ACKNOWLEDGMENTS}

We thank K. Mysore for providing the cNbME library in pTRV2, TRV1, and TRV2-gateway vector; G. Martin for providing PTO-transgenic $N$. benthamiana, 35S:PTOY207D, and TRV2 derivatives; B. Staskawicz for $P$. syrinagae pv. tabaci 11528 pPtDC38; K. Shirasu for pBin61_ AtSGT1a, pBin61_AtSGT1b, and anti-SGS antibody; J. Carrington for providing pSLJ:GFP; J. Lorang of the Wolpert lab for help constructing pEarleyGate100:RPP8 and reviewing the manuscript; A. Chu of the Wolpert lab for purification of victorin $\mathrm{C}$ and technical support; and the ABRC for providing GK_266H09 seed. This work was supported, in part, by the Agriculture and Food Research Initiative Competitive Grants Program from the United States Department of Agriculture National Institute of Food and Agriculture grant 2008-35319-18651.

\section{LITERATURE CITED}

Aken, O. V., Zhang, B., Carrie, C., Uggalla, V., Paynter, E., Giraud, E., and Whelan, J. 2009. Defining the mitochondrial stress response in Arabidopsis thaliana. Mol. Plant 2I1310-1324.

Anand, A., Vaghchhipawala, Z., Ryu, C.-M., Kang, L., Wang, K., delPozo, O., Martin, G. B., and Mysore, K. S. 2007. Identification and characterization of plant genes involved in Agrobacterium-mediated plant transformation by virus-induced gene silencing. Mol. PlantMicrobe Interact. 20:41-52.

Anand, A., Rojas, C. M., Tang, Y., and Mysore, K. S. 2012. Several components of SKP1/Cullin/F-box E3 ubiquitin ligase complex and associated factors play a role in Agrobacterium-mediated plant transformation. New Phytol. 195:203-216.

Arpagaus, S., Rawyler, A., and Braendle, R. 2002. Occurrence and characteristics of the mitochondrial permeability transition in plants. J. Biol. Chem. 277:1780-1787.

Austin, M. J., Muskett, P., Kahn, K., Feys, B. J., Jones, J. D. G., and Parker, J. E. 2002. Regulatory role of SGT1 in early $R$ gene-mediated plant defenses. Science 295:2077-2080.

Azevedo, C., Sadanandom, A., Kitagawa, K., Freialdenhoven, A., Shirasu, K., and Schulze-Lefert, P. 2002. The RAR1 interactor SGT1, an essential component of $R$ gene-triggered disease resistance. Science 295:2073-2076.

Azevedo, C., Betsuyaku, S., Peart, J., Takahashi, A., Noël, L., Sadanandom, A., Casais, C., Parker, J., and Shirasu, K. 2006. Role of SGT1 in resistance protein accumulation in plant immunity. EMBO (Eur. Mol. Biol. Organ.) J. 25:2007-2016.

Baulcombe, D. C. 1999. Fast forward genetics based on virus-induced gene silencing. Curr. Opin. Plant Biol. 2:109-113.

Besson-Bard, A., Pugin, A., and Wendehenne, D. 2008. New insights into nitric oxide signaling in plants. Annu. Rev. Plant Biol. 59:21-39.

Bieri, S., Mauch, S., Shen, Q.-H., Peart, J., Devoto, A., Casais, C., Ceron, F., Schulze, S., Steinbiß, H.-H., and Shirasu, K. 2004. RAR1 positively controls steady state levels of barley MLA resistance proteins and ena- 
bles sufficient MLA6 Accumulation for effective resistance. Plant Cell 16:3480-3495.

Bogdanove, A. J., and Martin, G. B. 2000. AvrPto-dependent Pto-interacting proteins and AvrPto-interacting proteins in tomato. Proc. Natl. Acad. Sci. U.S.A. 97:8836-8840.

Bolton, M. D. 2009. Primary metabolism and plant defense-fuel for the fire. Mol. Plant-Microbe Interact. 22:487-497.

Botër, M., Amigues, B., Peart, J., Breuer, C., Kadota, Y., Casais, C., Moore, G., Kleanthous, C., Ochsenbein, F., and Shirasu, K. 2007. Structural and functional analysis of SGT1 reveals that its interaction with HSP90 is required for the accumulation of $\mathrm{Rx}$, an $\mathrm{R}$ protein involved in plant immunity. Plant Cell 19:3791-3804.

Bourguignon, J., Rebeille, F., and Douce, R.1999. Serine and glycine metabolism in higher plants. Pages 111-146 in: Plant Amino Acids: Biochemistry and Biotechnology. B. K. Singh, ed. Marcel Dekker, New York

Calderini, O., Glab, N., Bergounioux, C., Heberle-Bors, E., and Wilson, C. 2001. A novel tobacco mitogen-activated protein (MAP) kinase kinase, NtMEK1, activates the cell cycle-regulated p43Ntf6 MAP kinase. J. Biol. Chem. 276:18139-18145

Coffeen, W. C., and Wolpert, T. J. 2004. Purification and characterization of serine proteases that exhibit caspase-like activity and are associated with programmed cell death in Avena sativa. Plant Cell 16:857-873.

Cooley, M. B., Pathirana, S., Wu, H.-J., Kachroo, P., and Klessig, D. F. 2000. Members of the Arabidopsis HRT/RPP8 family of resistance genes confer resistance to both viral and oomycete pathogens. Plant Cell 12:663-676.

Curtis, M. J., and Wolpert, T. J. 2002. The oat mitochondrial permeability transition and its implication in victorin binding and induced cell death. Plant J. 29:295-312.

Curtis, M. J., and Wolpert, T. J. 2004. The victorin-induced mitochondrial permeability transition precedes cell shrinkage and biochemical markers of cell death, and shrinkage occurs without loss of membrane integrity. Plant J. 38:244-259.

Dangl, J. L., and Jones, J. D. 2001. Plant pathogens and integrated defence responses to infection. Nature 411:826-833.

Dangl, J. L., and McDowell, J. M. 2006. Two modes of pathogen recognition by plants. Proc. Natl. Acad. Sci. U.S.A. 103:8575-8576.

Earley, K. W., Haag, J. R., Pontes, O., Opper, K., Juehne, T., Song, K., and Pikaard, C. S. 2006. Gateway-compatible vectors for plant functional genomics and proteomics. Plant J. 45:616-629.

Eulgem, T., Weigman, V. J., Chang, H.-S., McDowell, J. M., Holub, E. B., Glazebrook, J., Zhu, T., and Dangl, J. L. 2004. Gene expression signatures from three genetically separable resistance gene signaling pathways for downy mildew resistance. Plant Physiol. 135:11291144.

Foyer, C. H., Bloom, A. J., Queval, G., and Noctor, G. 2009. Photorespiratory metabolism: Genes, mutants, energetics, and redox signaling. Annu. Rev. Plant Biol. 60:455-484

Gabriëls, S. H. E. J., Vossen, J. H., Ekengren, S. K., van Ooijen, G., AbdEl-Haliem, A. M., van den Berg, G. C. M., Rainey, D. Y., Martin, G. B., Takken, F. L. W., and de Wit, P. J. G. M. 2007. An NB-LRR protein required for $\mathrm{HR}$ signaling mediated by both extra- and intracellular resistance proteins. Plant J. 50:14-28

Glazebrook, J. 2005. Contrasting mechanisms of defense against biotrophic and necrotrophic pathogens. Annu. Rev. Phytopathol. 43:205227.

Goodin, M. M., Zaitlin, D., Naidu, R. A., and Lommel, S. A. 2008. Nicotiana benthamiana: Its history and future as a model for plant-pathogen interactions. Mol. Plant-Microbe Interact. 21:1015-1026.

Govrin, E. M., and Levine, A. 2000. The hypersensitive response facilitates plant infection by the necrotrophic pathogen Botrytis cinerea. Curr. Biol. 10:751-757.

Gray, W. M., Muskett, P. R., Chuang, H., and Parker, J. E. 2003. Arabidopsis SGT1b is required for SCFTIR1-mediated auxin response. Plant Cell 15:1310-1319.

Greenberg, J. T., and Yao, N. 2004. The role and regulation of programmed cell death in plant-pathogen interactions. Cell. Microbiol. 6:201-211.

Heath, M. C. 2000. Hypersensitive response-related death. Plant Mol. Biol. 44:321-334.

Hubert, D. A., Tornero, P., Belkhadir, Y., Krishna, P., Takahashi, A. Shirasu, K., and Dangl, J. L. 2003. Cytosolic HSP90 associates with and modulates the Arabidopsis RPM1 disease resistance protein. EMBO (Eur. Mol. Biol. Organ.) J. 22, 5679-5689.

Hwang, N. R., Yim, S., Kim, Y. M., Jeong, J., Song, E. J., Lee, Y., Lee, J. H., Choi, S., and Lee, K. 2009. Oxidative modifications of glyceraldehyde-3-phosphate dehydrogenase play a key role in its multiple cellular functions. Biochem. J. 423:253-264.

Ji, C., Boyd, C., Slaymaker, D., Okinaka, Y., Takeuchi, Y., Midland, S. L.,
Sims, J. J., Herman, E., and Keen, N. 1998. Characterization of a 34 $\mathrm{kDa}$ soybean binding protein for the syringolide elicitors. Proc. Natl. Acad. Sci. U.S.A. 95:3306-3311.

Jin, H., Axtell, M. J., Dahlbeck, D., Ekwenna, O., Zhang, S., Staskawicz, B., and Baker, B. 2002. NPK1, an MEKK1-like mitogen-activated protein kinase kinase kinase, regulates innate immunity and development in plants. Dev. Cell 3:291-297.

Jones, J. D. G., and Dangl, J. L. 2006. The plant immune system. Nature 444:323-329.

Kadota, Y., Amigues, B., Ducassou, L., Madaoui, H., Ochsenbein, F., Guerois, R., and Shirasu, K. 2008. Structural and functional analysis of SGT1-HSP90 core complex required for innate immunity in plants. EMBO (Eur. Mol. Biol. Organ.) Rep. 9:1209-1215.

Kangasjärvi, S., Neukermans, J., Li, S., Aro, E.-M., and Noctor, G. 2012. Photosynthesis, photorespiration, and light signalling in defence responses. J. Exp. Bot. 63:1619-1636.

Keon, J., Antoniw, J., Carzaniga, R., Deller, S., Ward, J. L., Baker, J.M., Beale, M. H., Hammond-Kosack, K., and Rudd, J. J. 2007. Transcriptional adaptation of Mycosphaerella graminicola to programmed cell death (PCD) of its susceptible wheat host. Mol. Plant-Microbe Interact. 20:178-193.

Kim, J. H., Lee, S., Park, J. B., Lee, S. D., Kim, J. H., Ha, S. H., Hasumi, K., Endo, A., Suh, P.-G., and Ryu, S. H. 2003. Hydrogen peroxide induces association between glyceraldehyde 3-phosphate dehydrogenase and phospholipase D2 to facilitate phospholipase D2 activation in PC12 cells. J. Neurochem. 85:1228-1236.

King, E. O., Ward, M. K., and Raney, D. E. 1954. Two simple media for the demonstration of pyocyanin and fluorescin. J. Lab. Clin. Med. 44:301-307.

Kinkema, M., Fan, W., and Dong, X. 2000. Nuclear localization of NPR1 is required for activation of PR gene expression. Plant Cell 12:23392350 .

Kozaki, A., and Takeba, G. 1996. Photorespiration protects C3 plants from photooxidation. Nature 384:557-560.

Leister, R. T., Dahlbeck, D., Day, B., Li, Y., Chesnokova, O., and Staskawicz, B. J. 2005. Molecular genetic evidence for the role of SGT1 in the intramolecular complementation of Bs2 protein activity in Nicotiana benthamiana. Plant Cell 17:1268-1278.

Leung, A. W. C., and Halestrap, A. P. 2008. Recent progress in elucidating the molecular mechanism of the mitochondrial permeability transition pore. Biochim. Biophys. Acta 1777:946-952.

Litzenberger, S. C. 1949. Nature of susceptibility to Helminthosporium victoriae and resistance to Puccinia coronata in Victoria oats. Phytopathology 39:300-318.

Liu, Y., Schiff, M., Marathe, R., and Dinesh-Kumar, S. P. 2002. Tobacco Rar1, EDS1 and NPR1/NIM1 like genes are required for N-mediated resistance to Tobacco mosaic virus. Plant J. 30:415-429.

Lorang, J., Kidarsa, T., Bradford, C. S., Gilbert, B., Curtis, M., Tzeng, S.-C., Maier, C. S., and Wolpert, T. J. 2012. Tricking the guard: Exploiting plant defense for disease susceptibility. Science 338:659-662.

Lorang, J. M., Carkaci-Salli, N., and Wolpert, T. J. 2004. Identification and characterization of victorin sensitivity in Arabidopsis thaliana. Mol. Plant-Microbe Interact. 17:577-582.

Lorang, J. M., Sweat, T. A., and Wolpert, T .J. 2007. Plant disease susceptibility conferred by a "resistance" gene. Proc. Natl. Acad. Sci. U.S.A. 104:14861-14866.

Lu, R., Martin-Hernandez, A. M., Peart, J. R., Malcuit, I., and Baulcombe, D. C. 2003. Virus-induced gene silencing in plants. Methods 30:296 303.

Luke, H. H., Murphy, H. C., and Petr, F. C. 1966. Inheritance of spontaneous mutations of the Victoria locus in oats. Phytopathology 56:210212.

Luo, Y., Caldwell, K. S., Wroblewski, T., Wright, M. E., and Michelmore, R. W. 2009. Proteolysis of a negative regulator of innate immunity is dependent on resistance genes in tomato and Nicotiana benthamiana and induced by multiple bacterial effectors. Plant Cell 21:2458-2472.

Macko, V., Wolpert, T. J., Acklin, W., Jaun, B., Seibl, J., Meili, J., and Arigoni, D. 1985. Characterization of victorin C, the major host-selective toxin from Cochliobolus victoriae: Structure of degradation products. Experientia 41:1366-1370.

Mayama, S., Tani, T., Ueno, T., Midland, S. L., Sims, J. J., and Keen, N. T. 1986. The purification of victorin and its phytoalexin elicitor activity in oat leaves. Physiol. Mol. Plant Pathol. 29:1-18.

Mayama, S., Bordin, A. P. A., Morikawa, T., Tanpo, H., and Kato, H. 1995. Association of avenalumin accumulation with co-segregation of victorin sensitivity and crown rust resistance in oat lines carrying the Pc-2 gene. Physiol. Mol. Plant Pathol. 46:263-274.

McDowell, J. M., Dhandaydham, M., Long, T. A., Aarts, M. G., Goff, S., Holub, E. B., and Dangl, J. L. 1998. Intragenic recombination and 
diversifying selection contribute to the evolution of downy mildew resistance at the RPP8 locus of Arabidopsis. Plant Cell 10:1861-1874.

Meehan, F., and Murphy, H. C. 1946. A new Helminthosporium blight of oats. Science 104:413-414.

Meehan, F., and Murphy, H. C. 1947. Differential phytotoxicity of metabolic by-products of Helminthosporium victoriae. Science 106:270271

Mestre, P., and Baulcombe, D. C. 2006. Elicitor-mediated oligomerization of the tobacco N disease resistance Protein. Plant Cell 18:491-501.

Mur, L. A. J., Kenton, P., Lloyd, A. J., Ougham, H., and Prats, E. 2008 The hypersensitive response; the centenary is upon us but how much do we know? J. Exp. Bot. 59:501-520.

Navarre, D. A., and Wolpert, T. J. 1995. Inhibition of the glycine decarboxylase multienzyme complex by the host-selective toxin victorin. Plant Cell 7:463-471.

Navarre, D. A., and Wolpert, T. J. 1999a. Victorin induction of an apoptotic/senescence-like response in oats. Plant Cell 11:237-249.

Navarre, D. A., and Wolpert, T. J. 1999b. Effects of light and $\mathrm{CO}_{2}$ on victorin-induced symptom development in oats. Physiol. Mol. Plant Pathol. 55:237-242.

Nimchuk, Z., Eulgem, T., Holt, B. F., 3rd, and Dangl, J. L. 2003. Recognition and response in the plant immune system. Annu. Rev. Genet. 37:579-609.

Noctor, G., Veljovic-Jovanovic, S., Driscoll, S., Novitskaya, L., and Foyer, C. H. 2002. Drought and oxidative load in the leaves of C3 plants: A predominant role for photorespiration? Ann. Bot. 89:841-850.

Noël, L. D., Cagna, G., Stuttmann, J., Wirthmüller, L., Betsuyaku, S., Witte, C.-P., Bhat, R., Pochon, N., Colby, T., and Parker, J. E. 2007. Interaction between SGT1 and cytosolic/nuclear HSC70 chaperones regulates Arabidopsis immune responses. Plant Cell 19:4061-4076.

Oirdi, M., and Bouarab, K. 2007. Plant signalling components EDS1 and SGT1 enhance disease caused by the necrotrophic pathogen Botrytis cinerea. New Phytol. 175:131-139.

Okinaka, Y., Yang, C.-H., Herman, E., Kinney, A., and Keen, N. T. 2002 The P34 syringolide elicitor receptor interacts with a soybean photorespiration enzyme, NADH-dependent hydroxypyruvate reductase. Mol. Plant-Microbe Interact. 15:1213-1218.

Palmieri, M. C., Lindermayr, C., Bauwe, H., Steinhauser, C., and Durner, J. 2010. Regulation of plant glycine decarboxylase by S-nitrosylation and glutathionylation. Plant Physiol. 152:1514-1528.

Peart, J. R., Lu, R., Sadanandom, A., Malcuit, I., Moffett, P., Brice, D. C., Schauser, L., Jaggard, D. A. W., Xiao, S., and Coleman, M. J. 2002. Ubiquitin ligase-associated protein SGT1 is required for host and nonhost disease resistance in plants. Proc. Natl. Acad. Sci. U.S.A. 99:10865-10869.

Pozo, O. del, Pedley, K. F., and Martin, G. B. 2004. MAPKKK $\alpha$ is a positive regulator of cell death associated with both plant immunity and disease. EMBO (Eur. Mol. Biol. Organ.) J. 23:3072-3082.

Rathjen, J. P., Chang, J. H., Staskawicz, B. J., and Michelmore, R. W. 1999. Constitutively active Pto induces a Prf-dependent hypersensitive response in the absence of avrPto. EMBO (Eur. Mol. Biol. Organ.) J. 18:3232-3240.

Rines, H. W., and Luke, H. H. 1985. Selection and regeneration of toxininsensitive plants from tissue cultures of oats. TAG Theor. Appl. Genet. 71:16-21.

Rojas, C. M., Senthil-Kumar, M., Wang, K., Ryu, C.-M., Kaundal, A., and Mysore, K. S. 2012. Glycolate oxidase modulates reactive oxygen species-mediated signal transduction during nonhost resistance in Nicotiana benthamiana and Arabidopsis. Plant Cell 24:336-352

Romanko, R. R. 1959. A physiological basis for resistance of oats to Victoria blight. Phytopathology 49:32-36.

Ronald, P. C., Salmeron, J. M., Carland, F. M., and Staskawicz, B. J. 1992. The cloned avirulence gene avrPto induces disease resistance in tomato cultivars containing the Pto resistance gene. J. Bacteriol. 174:16041611.

Rudd, J. J., Keon, J., and Hammond-Kosack, K. E. 2008. The wheat mitogen-activated protein kinases TaMPK3 and TaMPK6 are differentially regulated at multiple levels during compatible disease interactions with Mycosphaerella graminicola. Plant Physiol. 147:802-815.

Salmeron, J. M., Oldroyd, G. E., Rommens, C. M., Scofield, S. R., Kim, H. S., Lavelle, D. T., Dahlbeck, D., and Staskawicz, B. J. 1996. Tomato Prf is a member of the leucine-rich repeat class of plant disease resistance genes and lies embedded within the Pto kinase gene cluster. Cell 86:123-133

Scott, I., and Logan, D. C. 2008. Mitochondrial morphology transition is an early indicator of subsequent cell death in Arabidopsis. New Phytol. 177:90-101

Seo, Y.-S., Lee, S.-K., Song, M.-Y., Suh, J.-P., Hahn, T.-R., Ronald, P., and Jeon, J.-S. 2008. The HSP90-SGT1-RAR1 molecular chaperone complex: A core modulator in plant immunity. J. Plant Biol. 51:1-10.
Shain, L., and Wheeler, H. 1975. Production of ethylene by oats resistant and susceptible to victorin. Phytopathology 65:88-89.

Shirasu, K. 2009. The HSP90-SGT1 chaperone complex for NLR immune sensors. Annu. Rev. Plant Biol. 60:139-164.

Shirasu, K., and Schulze-Lefert, P. 2003. Complex formation, promiscuity and multi-functionality: Protein interactions in disease-resistance pathways. Trends Plant Sci. 8:252-258

Swarbrick, P. J., Schulze-Lefert, P., and Scholes, J. D. 2006. Metabolic consequences of susceptibility and resistance (race-specific and broadspectrum) in barley leaves challenged with powdery mildew. Plant Cell Environ. 29:1061-1076.

Sweat, T. A., and Wolpert, T. J. 2007. Thioredoxin h5 is required for victorin sensitivity mediated by a CC-NBS-LRR gene in Arabidopsis. Plant Cell 19:673-687.

Tada, Y., Hata, S., Takata, Y., Nakayashiki, H., Tosa, Y., and Mayama, S. 2001. Induction and signaling of an apoptotic response typified by DNA laddering in the defense response of oats to infection and elicitors. Mol. Plant Microbe Interact. 14:477-486.

Tada, Y., Spoel, S. H., Pajerowska-Mukhtar, K., Mou, Z., Song, J., Wang, C., Zuo, J., and Dong, X. 2008. plant immunity requires conformational charges of NPR1 via S-nitrosylation and thioredoxins. Science 321:952-956

Takahashi, A., Casais, C., Ichimura, K., and Shirasu, K. 2003. HSP90 interacts with RAR1 and SGT1 and is essential for RPS2-mediated disease resistance in Arabidopsis. Proc. Natl. Acad. Sci. U.S.A. 100:1177711782.

Takahashi, H., Miller, J., Nozaki, Y., Sukamto, Takeda, M., Shah, J., Hase, S., Ikegami, M., Ehara, Y., and Dinesh-Kumar, S. P. 2002. RCY1, an Arabidopsis thaliana $R P P 8 / H R T$ family resistance gene, conferring resistance to Cucumber mosaic virus requires salicylic acid, ethylene and a novel signal transduction mechanism. Plant J. 32:655-667.

Taler, D., Galperin, M., Benjamin, I., Cohen, Y., and Kenigsbuch, D. 2004. Plant eR genes that encode photorespiratory enzymes confer resistance against disease. Plant Cell 16:172-184.

Tiwari, B. S., Belenghi, B., and Levine, A. 2002. Oxidative stress increased respiration and generation of reactive oxygen species, resulting in ATP depletion, opening of mitochondrial permeability transition, and programmed cell death. Plant Physiol. 128:1271-1281.

Tornero, P., Chao, R. A., Luthin, W. N., Goff, S. A., and Dangl, J. L. 2002. Large-scale structure-function analysis of the Arabidopsis RPM1 disease resistance protein. Plant Cell 14:435-450.

Torres, M. A., Jones, J. D. G., and Dangl, J. L. 2006. Reactive oxygen species signaling in response to pathogens. Plant Physiol. 141:373-378.

Ullrich, C. I., and Novacky, A. J. 1991. Electrical membrane properties of leaves, roots, and single root cap cells of susceptible Avena sativa: Effect of victorin C. Plant Physiol. 95:675-681.

Varanyuwatana, P., and Halestrap, A. P. 2012. The roles of phosphate and the phosphate carrier in the mitochondrial permeability transition pore. Mitochondrion 12:120-125.

Walton, J. D., and Earle, E. D. 1985. Stimulation of extracellular polysaccharide synthesis in oat protoplasts by the host-specific phytotoxin victorin. Planta 165:407-415.

Welsh, J. N., Peturson, B., and Machacek, J. E. 1954. Associated inheritance of reaction to races of crown rust, Puccinia coronata avenae Erikss., and to Victoria blight, Helminthosporium victoriae $\mathrm{M}$. and $\mathrm{M}$. in oats. Can. J. Bot. 32:55-68.

Wheeler, H., and Black, H. S. 1963. Effects of Helminthosporium victoriae and victorin upon permeability. Am. J. Bot. 50:686.

Wolpert, T., Lorang, J., Sweat, T., Gilbert, B., Chu, A., and Bradford, C. 2011. Analysis of a plant susceptibility response and its similarities to resistance. Pages 21-32 in: Genome Enabled Analysis of Plant-Pathogen Interactions. T. Wolpert, T. Shiraishi, A. Colmer, K. Akimitsu, and J. Glazebrook, eds. American Phytopathological Society Press, St. Paul, MN, U.S.A.

Wolpert, T. J., and Macko, V. 1989. Specific binding of victorin to a 100kDa protein from oats. Proc. Natl. Acad. Sci. U.S.A. 86:4092-4096.

Wolpert, T. J., Macko, V., Acklin, W., Jaun, B., Seibl, J., Meili, J., and Arigoni, D. 1985. Structure of victorin C, the major host-selective toxin from Cochliobolus victoriae. Cell. Mol. Life Sci. 41:1524-1529.

Wolpert, T. J., Dunkle, L. D., and Ciuffetti, L. M. 2002. Host-selective toxins and avirulence determinants: What's in a name? Annu. Rev. Phytopathol. 40:251-285.

Xu, H., Zhang, J., Zeng, J., Jiang, L., Liu, E., Peng, C., He, Z., and Peng, X. 2009. Inducible antisense suppression of glycolate oxidase reveals its strong regulation over photosynthesis in rice. J. Exp. Bot. 60:17991809

Yang, K.-Y., Liu, Y., and Zhang, S. 2001. Activation of a mitogen-activated protein kinase pathway is involved in disease resistance in tobacco. Proc. Natl. Acad. Sci. U.S.A. 98:741-746.

Yao, N., Tada, Y., Park, P., Nakayashiki, H., Tosa, Y., and Mayama, S. 
2001. Novel evidence for apoptotic cell response and differential signals in chromatin condensation and DNA cleavage in victorin-treated oats. Plant J. 28:13-26.

Yao, N., Tada, Y., Sakamoto, M., Nakayashiki, H., Park, P., Tosa, Y., and Mayama, S. 2002. Mitochondrial oxidative burst involved in apoptotic response in oats. Plant J. 30:567-579.

Zaffagnini, M., Michelet, L., Marchand, C., Sparla, F., Decottignies, P., Le Maréchal, P., Miginiac-Maslow, M., Noctor, G., Trost, P., and Lemaire, S. D. 2007. The thioredoxin-independent isoform of chloroplastic glyceraldehyde-3-phosphate dehydrogenase is selectively regulated by glutathionylation. FEBS (Fed. Eur. Biochem. Soc.) J. 274:212226.
Zaffagnini, M., Bedhomme, M., Groni, H., Marchand, C. H., Puppo, C. Gontero, B., Cassier-Chauvat, C., Decottignies, P., and Lemaire, S. D. 2012. Glutathionylation in the photosynthetic model organism Chlamydomonas reinhardtii: A proteomic survey. Mol. Cell Proteomics 11:M111.014142.

Zhang, M., Kadota, Y., Prodromou, C., Shirasu, K., and Pearl, L. H. 2010. Structural basis for assembly of Hsp90-Sgt1-CHORD protein complexes: Implications for chaperoning of NLR innate immunity receptors. Mol. Cell 39:269-281.

Zhang, S., Liu, Y., and Klessig, D. F. 2000. Multiple levels of tobacco WIPK activation during the induction of cell death by fungal elicitins. Plant J. 23:339-347. 